\title{
Children's Academic Achievement and Behavior Problems at the Intersection of Gender and Family Environment
}

Michael Kühhirt, University of Cologne, Germany

Markus Klein, University of Strathclyde, UK

Ibrahim Demirer, University of Cologne, Germany

Keywords:

Gender inequality, children, academic achievement, behavior problems, intersectionality

\begin{abstract}
Using data from the National Longitudinal Study of Youth, this article investigates whether gender differences in children's math, reading and behavior problems vary across mothers' education and family structure. Drawing on the framework of intersectionality, we expect that boys growing up with less educated mothers and in single-parent families may lag more strongly behind girls in reading and behavior problems. In math, they may be less ahead than their peers from more advantaged backgrounds. Our findings provide evidence for the expected heterogeneity of gender differences by maternal education but not by family structure. This may suggest that cultural norms connected to education are more important than family resources and the presence of (male) role models in explaining the observed heterogeneity across family circumstances. We replicated these findings for academic achievement with data from the Early Childhood Longitudinal Study.
\end{abstract}




\section{Children's Academic Achievement and Behavior Problems at the Intersection of Gender and Family Environment}

Gender differences in educational outcomes have long been a subject of great interest in a wide range of fields. Historically, girls obtained higher school grades than boys but were unable to translate this advantage into higher educational attainment (Alexander and Eckland 1974). Over time, girls' academic performance in high school has continuously improved while boys remained at the same level (Fortin, Oreopoulos, and Phipps 2015). Today, girls consistently outperform boys not only in grades but also in high school graduation, immediate college enrolment and college performance (Bozick and DeLuca 2005; Conger and Long 2010). Trends in college graduation also show a striking reversal of the gender gap that once favored males (Buchmann, DiPrete, and McDaniel 2008; Goldin, Katz, and Kuziemko 2006), partly due to women's lower dropout rate once enrolled in college (Buchmann and DiPrete 2006). Some scholars refer to this increasing male disadvantage as the "boy crisis" in educational attainment (e.g. Husain and Millimet 2009; Orr 2011). At the same time, women remain underrepresented in STEM majors and earn fewer STEM degrees (Ceci et al. 2014; Ceci, Williams, and Barnett 2009; Ceci and Williams 2011; Legewie and DiPrete 2014; Xie and Shauman 2003). Among other psychological and social factors, these differences are commonly attributed to societal beliefs about gender roles, which express themselves in differential expectations towards male and female students (Eccles, Jacobs, and Harold 1990; Tomasetto, Alparone, and Cadinu 2011), and to early gender gaps in behavioral and social skills (DiPrete and Jennings 2012; Jacob 2002).

When investigating the potential roots for different long-term educational pathways of men and women, studies focus on gender differences in children's academic achievement and 
behavior problems early in the life course. The evidence suggests that girls are disadvantaged in mathematics compared to boys, particularly at the top of the math distribution (Cimpian et al. 2016; Entwisle, Alexander, and Olson 1994; Gibbs 2010; Leahey and Guo 2001; Penner and Paret 2008). However, they outperform boys in reading (Downey and Yuan 2005; Entwisle, Alexander and Olson 2007) and show fewer behavioral problems than boys (Lahey et al. 2006; Lee 2010).

These gender differences in academic achievement may depend on the developmental stage and may change across childhood. For instance, gender differences in mathematics seem to increase with children's age (e.g., Fryer and Levitt 2010; Gibbs 2010). Only a few studies, however, followed children from elementary school to middle or high school and are thus concerned with the emergence and timing of gender differences in academic achievement and behavior problems (Cameron et al. 2015; Lahey et al. 2006; Leahey and Guo 2001; Robinson and Lubienski 2011; Zhang, Mcardle, and Nesselroade 2012).

There is evidence for significant variation of gender differences in academic achievement across countries (e.g., van Hek, Buchmann, and Kraaykamp 2019; Penner 2008; Stoet and Geary 2013). This heterogeneity suggests that gender differences in academic achievement do not follow a universal pattern and may depend on the context under which boys and girls grow up. So far, the literature hardly addressed the potential moderating role of the family environment. From an intersectional perspective, the child's gender does not influence children's lived experiences in isolation from other categories of social position (Hsin 2018). Hence, gender differences in academic achievement may depend on and manifest in conjunction with other status characteristics of the child and the family. Whereas there is abundant literature on the separate effects of socioeconomic status (SES) (e.g., Bradley and Corwyn 2002; Chmielewski 
2019) and gender (e.g., Leahey and Guo 2001; McIntosh et al. 2013) on children's academic achievement, "the interaction between gender and SES has attracted much less attention" (Entwisle, Alexander, and Olson 2007, p. 128). Few studies investigated whether gender differences in children's academic and behavioral outcomes differ across SES (DiPrete and Jennings 2012; Entwisle et al. 2007; Penner and Paret 2008), family structure (Autor et al. 2019; Bertrand and Pan 2013; Lundberg 2017) or race (Catsambis 1994; Fan, Chen, and Matsumoto 1997; Fryer and Levitt 2010; Hsin 2018; Penner and Paret 2008). However, none of these studies investigated whether gender disparities in academic outcomes and behavior develop differently across childhood depending on the family circumstances.

This article examines whether maternal education and family structure moderate gender differences in children's math achievement, reading, and behavior problems. We complement research on gender differences in educational outcomes by investigating whether gender gaps in academic achievement and behavior problems systematically vary across different family environments, at what stage of the early life course this variation occurs and how it may change over time. Investigating the intersection of gender and family circumstances provides us with further insights into the roots of gender differences in academic achievement. Using data from the National Longitudinal Study of Youth-Children and Young Adults (NLSY-CYA) allows us to follow children from kindergarten to middle school with up to five measurements of math, reading, and behavior problems. To assess the robustness of our findings, we replicated the analyses of academic achievement with the Early Childhood Longitudinal Study Kindergarten Class 1998-99 (ECLS-K). 


\section{EXPLANATIONS FOR GENDER DIFFERENCES IN ACADEMIC ACHIEVEMENT}

AND BEHAVIOR PROBLEMS

Most sociological research on gender differences in educational outcomes focuses on environmental factors and ignores innate differences between boys and girls (Buchmann et al. 2008). Physical differences in male and female brains are well-documented, e.g., in grey and white matter or structures such as the hypothalamus (Halpern 2011). Whereas boys have advantages in cognitive perception and visuospatial skills, girls have more advanced skills in speaking, reading, and use of more complex verbal construction (Halpern 2011). However, there is little evidence to suggest that physical differences between male and female brains are responsible for sex differences in cognition (Halpern 2011). Compared to more pronounced and robust sex differences in motor behavior or aggression, differences between boys and girls in cognition seem to be small (Hyde 2005, 2016; Spelke 2005). Recent studies did not find any intrinsic differences in early quantitative and mathematical ability between boys and girls (Bakker et al. 2018; Kersey et al. 2018). Overall, there is only little support for the assumption that biological differences are the main reason for sex differences in academic achievement. This evidence, however, cannot exclude the possibility that biological sex differences interact with environmental factors in shaping different learning outcomes (Buchmann et al. 2008).

Essential components in children's learning environment are parent-child interactions and activities. Parents may have different parenting styles depending on the gender of their child, and this differential treatment may result in gender-specific interests, personality, and skills (McHale, Crouter, and Tucker 1999). There is evidence that mothers talk more and use more supportive speech with girls than with boys (Leaper, Anderson, and Sanders 1998; Porche, Ross, and Snow. 2014). They also spend more time on teaching activities (e.g., reading, telling stories) 
with their daughters than with their sons (Baker and Milligan 2016; Fiorini and Keane 2014) and this accounts for a substantial part of gender differences in preschool reading and math scores (Baker and Milligan 2016). Girls are also more exposed to 'concerted cultivation' - a strategy of deliberate cognitive and social development (Lareau 2011) - than boys, and thus are more closely monitored in organizational activities (Cheadle and Amato 2010; see also Dumais 2002). On the other hand, Stevenson and Baker (1987) found that parents are more involved in their daughters' home activities but engage more in their sons' school activities. Parents also explain concepts of scientific thinking more frequently to boys than to girls resulting in a gender gap in children's scientific literacy (Crowley et al. 2001). They seem to spend more of their time with boys due to extra input from fathers, in particular for play and companionship activities (Lundberg 2005; Yeung et al. 2001). Whether differences in parenting styles lead to gender differences in academic outcomes or behavioral problems is, however, still for debate as parenting styles may be responsive to children's personalities and behavior.

Societal beliefs about gender roles and parental expectations may also influence gender differences in math, reading or behavior. Extensive research on Eccles' expectancy-value theory (Eccles et al. 1990; for an overview see Gunderson et al. 2012) showed that parents' mathrelated gender stereotypes shape their expectations and attributions for boys' and girls' math performance and, in turn, impact on children's expectations and achievement. Studies also found that parents' estimation of children's IQ was significantly higher for boys than for girls (Furnham, Reeves, and Budhani 2002) and that they are more likely to assume that science is less stimulating and more difficult for girls than for boys (Tenenbaum and Leaper 2003). Entwisle et al. (2007) also argued that gender differences in reading are partially due to parents' lower reading expectations towards boys. Results from a survey experiment also showed that 
parents believe that boys should receive more instructional resources and parental school involvement, whereas girls should receive more cultural and college resources (Quadlin 2018).

These societal beliefs about gender roles also shape children's educational identities (Cech et al. 2011) which, in turn, may affect their educational decisions or performance. Yavorsky and Buchmann (2019) showed that the more gender-typical boys' behavior is, the steeper the decline in their grade point average. Heyder and Kessels (2013) found that boys who associated schools with female traits and ascribed more negative masculine traits to themselves had lower grades than boys who did not.

Individuals of a negatively stereotyped group (e.g., females) may perform less well on a task (e.g., mathematics) when that stereotype is more salient (Steele 1997). The math-gender stereotype is acquired early in life and affects the emerging self-concept throughout adolescence (Cvencek, Meltzoff, and Greenwald 2011; Else-Quest, Mineo, and Higgins 2013). Meta-analyses of lab-based experiments showed that women have a lower math performance when exposed to internal or external stereotype threat (Doyle and Voyer 2016; Picho, Rodriguez, and Finnie 2013). Math performance under stereotype threat, however, depends on moderators such as gender identity (Wout et al. 2008) and gender-role orientation (Ehrtmann and Wolter 2018). That is girls who do not identify strongly with their gender and who have an egalitarian gender-role orientation perform better in mathematics under stereotype threat than their peers. However, studies did not find evidence for a negative impact of gender stereotype threat on mathematics performance among school-aged children in the U.S. (Ganley et al. 2013; Stricker and Ward 2008).

Gender stereotypes in society may also influence teacher expectations, which, in turn, impact on children's academic performance and behavior ( $\mathrm{Li} 1999$ ). There is evidence that 
teachers give boys more freedom to engage in physical activities and to behave the way they want, whereas girls are more involved in organized activities (Martin 1998). While teachers regard playful boys as rebellious and intrusive compared to their less playful counterparts, they do not make this distinction among girls (Barnett 2018). These gender stereotypes among teachers were found to harm boys' reading self-concept (Retelsdorf, Schwartz, and Asbrock 2015). Teachers also grade boys less favorably even when their performance is equal to girls' in reading, math, and science tests (Cornwell et al. 2014). Their gender biases in favor of girls have a strong impact on girls' progress in both math and literacy (Terrier 2016). However, when girls and boys have similar levels of achievement, they give girls' mathematical skills a lower rating than boys' skills (Cimpian et al. 2016). Despite these results, teacher expectation biases do not seem to play a substantial role in mediating gender gaps in reading and mathematics (Gentrup and Rjosk 2018).

The school and classroom environment may also have an impact on gender-specific learning. For instance, boys appear to profit more from increasing access to high-quality schooling regarding test scores and behavior than girls (Autor et al. 2019). Boys are more sensitive to school cultures and resources that foster stimulating learning environments and mitigate their negative school attitudes than girls than girls (Hsin 2018; Legewie and DiPrete 2012). Boys' reading performance also benefited more from a larger proportion of girls at school than girls' reading (van Hek, Kraaykamp, and Pelzer 2018).

Finally, the feminization of schools and, consequently, a lack of male role models may be harmful to boys' learning. While a few studies provide evidence for a same-sex teacher advantage (Dee 2005, 2006), the majority of studies did not find that boys perform better when taught by male teachers than by female teachers (Driessen 2007; Ehrenberg, Goldhaber, and 
Brewer 1995; Neugebauer, Helbig, and Landmann 2010; Sokal et al. 2007). Female teachers, however, seem to have a detrimental effect on female students' math achievement if they are anxious about math (Beilock et al. 2010).

\section{EMPIRICAL EVIDENCE ON GENDER GAPS}

A significant and growing body of literature investigated gender differences in mathematical skills. Some studies found that girls are disadvantaged compared to boys in math as early as Kindergarten (Morgan, Farkas, and Wu 2011; Penner and Paret 2008). However, there is an emerging consensus that their math skills do not differ at the beginning of elementary school but that boys have a faster acceleration rate than girls over time (Cameron et al. 2015; Cornwell et al. 2014; Fryer and Levitt 2010; Gibbs 2010; Lachance and Mazzocco 2006; Leahey and Guo 2001; Zhang et al. 2012). Girls also appear to struggle more than boys when recovering from shocks to their expected trajectories of math achievement (Kowaleski-Jones and Duncan 1999). Other research found that, initially, boys perform better in math only at the top of the distribution but that this male advantage spreads across the distribution throughout elementary school (Cimpian et al. 2016; Husain and Millimet 2009; Penner and Paret 2008; Robinson and Lubienski 2011). While some studies, did not find any gender differences in mathematics performance during middle and high school (Catsambis 1994; Hyde et al. 2008), other studies also suggest female disadvantages in these later school stages (Downey and Yuan 2005; Leahey and Guo 2001). There is evidence of greater variability in math scores among male than female students and male advantages seem be stronger among high-scoring youngsters (Ellison and Swanson 2010; Entwisle et al. 1994; Fan et al. 1997; Hyde et al. 2008). 
When it comes to reading, boys are disadvantaged compared to girls (Cornwell et al. 2014; Morgan et al. 2011) and this gap tends to grow during elementary school (Cameron et al. 2015; Chatterji 2006; Entwisle et al. 2007; Husain and Millimet 2009; Morgan, Farkas, and Hibel 2008). Downey and Yuan (2005) also identified this gender gap in reading test scores among middle and high school students. In contrast, Robinson and Lubieski (2011) found that reading gaps favoring females narrowed over time and only widened among low-achieving students.

Regarding behavioral outcomes, boys have lower levels of self-regulation of affect, behavior, and attention than girls (Else-Quest et al. 2006; Raffaelli, Crockett, and Shen 2005). They also show lower levels of sociability and compliance and greater hyperactivity, oppositional behavior and conduct problems (Arnett et al. 2015; Caughy et al. 2016; Lahey et al. 2006; Lee 2010; McIntosh et al. 2013). Boys are further more disruptive and less engaged in classroom learning than girls (Ready et al. 2005; Downey and Vogt Yuan 2005). Overall, boys tend to have more externalizing and internalizing behavior problems (e.g. arguing, fighting, getting angry) than girls, albeit gender differences in internalizing behavior problems are relatively small (Downey et al. 2019; Bertrand and Pan 2013; Entwisle et al. 2005). These early behavioral skills play an essential role in children's development as they influence later behavioral outcomes (Lee 2010). The gender gap in math and reading is also considerably reduced when accounting for social and behavioral skills (Bodovski and Youn 2011; Cornwell et al. 2014; DiPrete and Jennings 2012). Furthermore, antisocial behavior was more predictive of academic achievement for boys than for girls (Duncan and Magnuson 2011). Childhood behavior problems also have been found to impact the likelihood of repeating a grade in secondary school, 
completing high school or enrolling in college (Mcleod and Kaiser 2004; Shanahan 2000) and appear to explain the male disadvantage in educational attainment later in life (Owens 2016).

\section{CHILD DEVELOPMENT AT THE INTERSECTION OF GENDER AND FAMILY ENVIRONMENT}

In this article, we draw on intersectional approaches by assuming that multiple categories of social positions (e.g. gender and SES) are mutually constituted, reinforce each other and cannot be treated as separate units of analysis (Bauer 2014). The theory of intersectionality originated in feminist/gender studies but has been widely adopted and applied in other disciplines, including research on child development (Henry et al. 2019; Evans and Holt 2011). The intersectional approach thus differs from the unitary approach in which researchers consider one category of social position as primary interest and also from the multiple approach in which multiple categories add up to form layered disadvantages or privileges (Hancock 2007).

Evidence suggests that inequalities in education by gender interact with other axes of inequality. For instance, gender differences in academic achievement vary significantly across race and class at the high school and post-secondary levels (Autor et al. 2019; Riegle-Crumb 2006). What it means to be raised as a boy or a girl in our example, and the consequences it has on children's development, may vary across their socioeconomic circumstances. Investigating gender differences in academic achievement and behavior without considering that several social categories may intersect with each other would thus not adequately describe the lived experiences of boys and girls across their childhood.

Growing up in disadvantaged families may have a stronger negative impact on the development of boys than on the development of girls (Autor et al. 2019). There are two possible 
reasons for this intersection between gender and family disadvantage that are not mutually exclusive and potentially impact on each other. First, boys may naturally be more susceptible in their development to adverse environmental conditions compared to girls. Second, parental investments in boys versus girls may systematically vary with family resources. Parents in disadvantaged households may spend more time in educational activities with girls relative to boys, whereas parents with more advanced resources may compensate for boys' immaturity with larger investments compared to girls. ${ }^{1}$

Reinforcement of gender-typical socialization in children may also vary across different educational backgrounds (Entwisle et al. 2007). Highly educated people are known to have more liberal and egalitarian attitudes towards gender roles than individuals with lower qualifications (Bolzendahl and Myers 2007; Brewster and Padavic 2000; Brooks and Bolzendahl 2004). As outlined in the previous section, parents' gender stereotypes shape their parent-child interactions and expectations regarding academic achievement and behavior. Consequently, the disadvantage of boys in academic achievement and behavior may be much stronger among low-educated parents than among the highly educated.

High-SES parents spend more time on activities (e.g., reading for pleasure) that will help their sons succeed in school than low-SES parents (Entwisle et al. 2007). The support for education that middle-class parents equally give to both sons and daughters may remediate the alienation that boys generally feel towards school. Boys may also be more disadvantaged in single-mother households than girls due to a lack of a same-sex role model (Autor et al. 2019). Evidence also suggests that mothers spend more time with daughters and fathers spend more time with their sons, which leaves them at a disadvantage in single-mother households (Baker and Milligan 2016; Bertrand and Pan 2013). 
Figure 1 provides a stylized summary of the theoretical expectations regarding the intersection of gender and family environment in determining academic achievement and behavior problems. Overall, we expect that, compared to boys from more advantaged households, boys growing up in disadvantaged families lag more strongly behind girls in areas where they are commonly disadvantaged (reading, behavior problems) and are less ahead of girls in areas where they commonly have advantages (math).

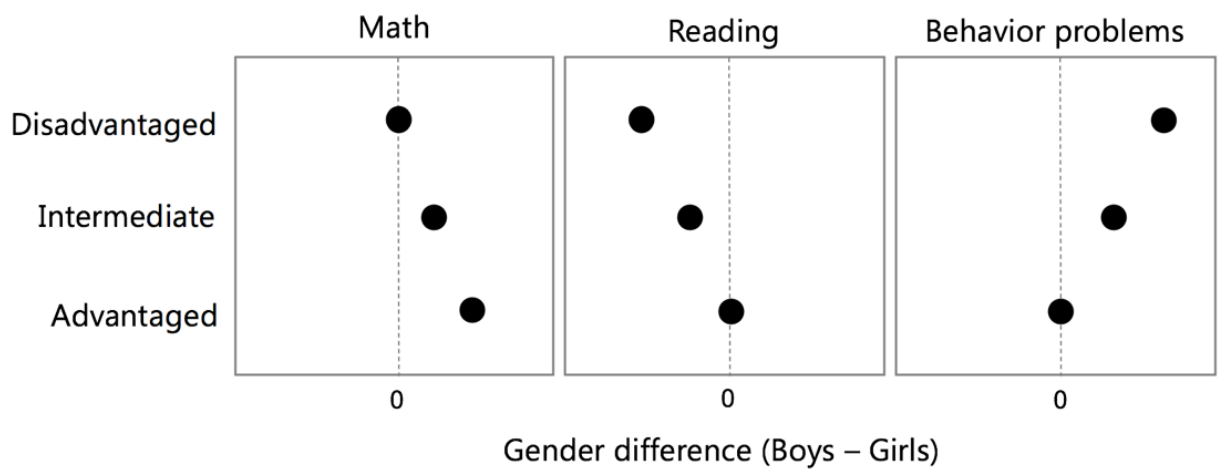

Figure 1. Stylized theoretical expectations regarding variation in gender differences in academic achievement and behavioral problems by family background

\section{EMPIRICAL EVIDENCE ON INTERSECTIONALITY IN CHILD DEVELOPMENT}

There is little literature investigating whether family environment stratifies gender differences in academic achievement. Family disadvantage - measured as low-SES or a single-parent household - seems to have a disproportionately negative impact on behavioral and educational outcomes of school-aged boys relative to girls (Autor et al. 2019; Bertrand and Pan 2013; Fryer and Levitt 2010; Lundberg 2017). Entwisle et al. (2007) showed that elementary school boys do about the same in reading test scores as girls among high-SES students but are disadvantaged among low-SES students. In contrast, DiPrete and Jennings (2012) showed that girls have higher 
reading scores than boys across all levels of SES. Regarding mathematics achievement, Penner and Paret (2008) showed that the male advantage in mathematics is the largest among highly educated parents. Reardon et al. (2018) found that the male advantage in mathematics is more substantial in socioeconomically advantaged school districts than it is in disadvantaged districts. Boys are also more sensitive to peer SES class composition than girls when investigating reading test scores (DiPrete and Legewie 2012).

Some scholars investigated whether gender differences in academic achievement and behavior problems differ across race. Compared to White students, Hsin (2018) did not see a male disadvantage in academic achievement among Asian American students during elementary school. However, she found that Asian American boys were underperforming relative to Asian American girls in later school stages. Catsambis (1994) found that the male advantage in math was largest among Hispanics and lowest among Black students. Penner and Paret (2008) showed that Asian-American kindergartners had the largest male advantage at the top of the mathematics distribution, whereas it was Hispanic girls with an advantage over boys at the top of the distribution. Other studies did not find any heterogeneity in gender differences in mathematics across races (Fan et al. 1997; Fryer and Levitt 2010). Lastly, Womack et al. (2018) showed that early childhood changes in family structure predicted elevated internalizing and externalizing problems in later ages, but only for Caucasian children.

\section{DATA}

The empirical analyses are based on data from the National Longitudinal Survey of Youth 1979 (NLSY79), a cohort study of men and women born between 1957 and 1964 and living in the United States in 1978 (Rothstein, Carr, and Cooksey 2019). The initial sample consisted of 6,111 
respondents representing the noninstitutionalized civilian population and 5,295 respondents oversampled to represent the subpopulations of Hispanic, Black, and economically disadvantaged non-Hispanic and non-Black civilians. After the first interview in 1979, interviews took place annually until 1994 and biennially after that with the most recent data available from $2016 .^{2}$

From 1986 onwards, the study was supplemented with biennial surveys of more than 11,500 children born to female respondents of the NLSY79. The NLSY-Children and Young Adults (NLSY-CYA) data include direct assessments of children's academic achievement in mathematics and reading and information on behavior problems as reported by the adult respondent, usually the mother. Both types of assessments were repeated up to five times, between the ages of 5 and 14 and 4 and 13, respectively, making these data one of the most commonly used sources for US studies of child development.

We limited our analyses to observations from children born between 1980 and 2002 who participated in the survey at the age of first eligibility for the assessments (age five to six for academic assessment; age four to five for the behavior assessment). This ensured that the children under study could complete all five assessments. For the same reason, we excluded children from the sample who were not assessed at the youngest age eligible. We then followed the sample of children until they completed the respective fifth assessment or were lost to follow-up. The loss to follow-up included temporary or permanent attrition but also having a missing value on any covariate or the respective assessment. ${ }^{3}$

\section{Variables}

Academic achievement. We used two achievement measures taken from the Peabody Individual Achievement Test (PIAT): mathematics and reading recognition (Dunn and Markwardt 1970), 
which were first administered to children aged five and older. The mathematics assessment presents children with 84 multiple-choice items covering topics such as recognizing numerals, geometry, and trigonometry. The reading recognition assessment measures word recognition and pronunciation using 84 items, each with four options. The child enters each assessment at an ageappropriate item and then proceeds until they respond incorrectly to five out of seven items. Our analyses used the raw score for these assessments.

Behavior problems. We used two subscales measuring a child's tendency to internalize problems or externalize behaviors that were derived by Guttmannova, Szanyi, and Cali (2008) from 17 of the 28 items of the Behavior Problems Index (BPI) (Peterson and Zill 1986) used in the NLSY. ${ }^{4}$ The internalizing subscale consists of items such as whether the child is too fearful or anxious; unhappy, sad, or depressed; and high-strung, tense, nervous. Items like whether the child cheats or tells lies; bullies or is cruel/mean to others; and argues too much comprise the externalizing subscale. The raw scores we used in the analyses were obtained by summing up mothers' responses to items comprising each scale based on the answer options (0) not true, (1) sometimes true, and (2) often true. ${ }^{5}$

Family characteristics. We capture differences in children's family environment around birth by using information on maternal education and the family structure. Mother's education is operationalized with the following categories: (1) no degree, (2), high school degree, (3) some college, and (4) four-year college degree or higher. For family structure, we distinguish between one-parent and two-parent families. We also included the mother's year of birth as a control variable.

Child characteristics. The variables capturing children's characteristics include gender (Girl, Boy), race (Hispanic, Black, Other), and year of birth (1980-1983, 1984-1988, 1989-1994, 
1995-2002). We also control for age at the time of assessment (in months) and the year of the survey.

\section{METHODS}

Our primary analysis is based on a series of weighted linear regression models that regress the respective raw score at a specific assessment on child and family characteristics. The first series of models focused on the intersection of child's gender and maternal education and predicts the conditional mean score from child's race, $R_{i}$, maternal education, $E_{i}$, child's gender, $G_{i}$, and the remaining covariates, $X_{i}$ :

$E\left(S_{i} \mid R_{i}, E_{i}, G_{i}, X_{i}\right)=\alpha+\boldsymbol{R}_{i} \boldsymbol{\delta}+\boldsymbol{E}_{i} \boldsymbol{\vartheta}+\boldsymbol{R}_{\boldsymbol{i}} \boldsymbol{E}_{i} \boldsymbol{\eta}+G_{i}\left(\gamma+\boldsymbol{R}_{\boldsymbol{i}} \boldsymbol{\theta}+\boldsymbol{E}_{\boldsymbol{i}} \boldsymbol{\zeta}+\boldsymbol{R}_{\boldsymbol{i}} \boldsymbol{E}_{\boldsymbol{i}} \boldsymbol{\tau}\right)+\boldsymbol{X}_{\boldsymbol{i}} \boldsymbol{\beta}$.

Because these models include multiple interaction terms between gender, maternal education, and race, they allow predicting group-specific mean scores for boys and girls as well as groupspecific gender differences in these mean scores averaged over the remaining covariates. Varying gender coefficients, education coefficients, and their interaction coefficients by race helps us to distinguish heterogeneous gender differences across mother's education from heterogeneous disparities by race. It further allows us to investigate the intersection of gender and family environment for each racial group separately, thereby avoiding potential bias following from oversampling of Blacks and Hispanics in the NLSY.

To investigate the intersection of gender and family structure, we extended the models from equation 1 with the binary indicator described above and respective two-way and three-way interaction terms with the child's gender and race. All models use standard errors clustered by the mother to quantify statistical uncertainty. 
To correct for systematic loss to follow-up, we used weights containing the inverse probability of remaining in the sample in the next wave conditional on the respective outcome measure, child's gender and age, and all covariates. This probability was estimated using a pooled logistic regression model predicting remaining in the sample in the next wave from the variables described above. Weighting the sample in this way created a pseudo-population in which loss to follow-up is independent of the variables included in the prediction model, thus avoiding bias from systematic attrition based on the observed variables.

We replicated the analyses of math and reading with data from the Early Childhood Longitudinal Study, Kindergarten Class 1998-99 (ECLS-K) to assess the robustness of our estimates beyond measures of statistical uncertainty. We refrained from using measures of externalizing and internalizing behavior from the ECLS-K as these were reported by teachers and are thus not comparable with the behavioral information provided by mothers in the NLSYCYA. Further information on the ECLS-K is provided in Appendix B.

\section{RESULTS}

\section{Sample description}

Although sample sizes vary depending on the respective outcome considered (see Appendix A), the distribution of covariates is very similar across samples. While roughly half of the children are neither Hispanic $(\sim 20 \%)$ nor Black $(\sim 30 \%)$, around $45 \%$ of children have mothers who completed a high school degree when they were born ( $\sim 20 \%$ no degrees, $\sim 20 \%$ some college, $\sim 15 \%$ college degree), and about $70 \%$ of children were born into two-parent households. 
Table 1. Summary Statistics for Academic Achievement Scores by Gender

\begin{tabular}{|c|c|c|c|c|c|c|c|}
\hline & \multicolumn{2}{|c|}{ All } & \multicolumn{2}{|c|}{ Girls } & \multicolumn{2}{|c|}{ Boys } & \multirow[b]{2}{*}{ p-value } \\
\hline & $\mathrm{M}$ & (sd) & $\mathrm{M}$ & (sd) & $\mathrm{M}$ & (sd) & \\
\hline \multicolumn{8}{|l|}{ Math } \\
\hline Age 5/6 & 15.30 & $(6.58)$ & 15.50 & $(6.46)$ & 15.10 & $(6.70)$ & 0.01 \\
\hline Age $7 / 8$ & 30.56 & $(10.62)$ & 30.64 & $(10.34)$ & 30.49 & $(10.90)$ & 0.60 \\
\hline Age $9 / 10$ & 44.18 & (10.69) & 43.88 & $(10.13)$ & 44.48 & (11.23) & 0.05 \\
\hline Age 11/12 & 52.08 & $(10.85)$ & 51.64 & $(10.34)$ & 52.53 & (11.33) & 0.01 \\
\hline Age $13 / 14$ & 56.43 & (11.79) & 55.65 & (11.33) & 57.25 & $(12.20)$ & 0.00 \\
\hline \multicolumn{8}{|c|}{ Reading recognition } \\
\hline Age $5 / 6$ & 16.99 & $(6.91)$ & 17.53 & $(6.84)$ & 16.47 & (6.94) & 0.00 \\
\hline Age $7 / 8$ & 33.41 & $(10.83)$ & 34.41 & $(10.57)$ & 32.42 & (10.99) & 0.00 \\
\hline Age $9 / 10$ & 46.21 & $(12.65)$ & 47.27 & $(12.05)$ & 45.12 & (13.15) & 0.00 \\
\hline Age 11/12 & 55.71 & (13.74) & 56.68 & (12.77) & 54.71 & (14.59) & 0.00 \\
\hline Age 13/14 & 61.92 & $(13.85)$ & 62.86 & $(12.73)$ & 60.94 & $(14.86)$ & 0.00 \\
\hline \multicolumn{8}{|c|}{ Externalizing problems } \\
\hline Age $4 / 5$ & 4.57 & $(3.23)$ & 4.42 & $(3.15)$ & 4.72 & $(3.31)$ & 0.00 \\
\hline Age 6/7 & 4.57 & $(3.50)$ & 4.29 & $(3.32)$ & 4.85 & $(3.66)$ & 0.00 \\
\hline Age 8/9 & 4.52 & $(3.55)$ & 4.19 & $(3.34)$ & 4.86 & $(3.73)$ & 0.00 \\
\hline Age 10/11 & 4.38 & $(3.57)$ & 4.10 & $(3.34)$ & 4.66 & $(3.76)$ & 0.00 \\
\hline Age $12 / 13$ & 4.01 & $(3.28)$ & 3.89 & $(3.19)$ & 4.12 & $(3.36)$ & 0.03 \\
\hline \multicolumn{8}{|c|}{ Internalizing problems } \\
\hline Age $4 / 5$ & 1.51 & $(1.84)$ & 1.55 & $(1.86)$ & 1.48 & $(1.83)$ & 0.16 \\
\hline Age $6 / 7$ & 1.71 & $(2.04)$ & 1.67 & $(2.00)$ & 1.75 & $(2.08)$ & 0.13 \\
\hline Age 8/9 & 1.74 & $(2.12)$ & 1.71 & $(2.09)$ & 1.77 & $(2.16)$ & 0.32 \\
\hline Age 10/11 & 1.70 & $(2.12)$ & 1.67 & $(2.10)$ & 1.73 & $(2.13)$ & 0.35 \\
\hline Age $12 / 13$ & 1.57 & $(2.04)$ & 1.55 & $(1.98)$ & 1.59 & $(2.10)$ & 0.52 \\
\hline
\end{tabular}

Note: P-values pertain to two-tailed t-tests of mean differences by gender.

Table 1 shows the mean scores for academic achievement and behavioral problems by age period and gender along with the p-values of two-tailed t-tests. For math, boys' small initial disadvantage over girls turns into a growing advantage over the observation period. Boys' 
average reading score is significantly lower than girls' average score at any age. Boys have consistently higher scores for externalizing problems than girls. While their score for internalizing problems is also higher, except for the first age period, the mean difference is not statistically significant at any point in time.

\section{Gender differences by maternal education}

Figure 2 shows the average adjusted math scores for boys and girls by maternal education along with the respective gender difference and its $95 \%$ confidence interval. All mean scores and gender differences in mean scores are predictions from the model described by equation 1 . At the first assessment around age 5/6, girls slightly outperform boys across all groups, reflecting their overall advantage shown in Table 1. Over time, boys first gain an advantage in math among children whose mothers have some college and then also among those whose mothers have high school and college degrees. Among children whose mothers have high school degrees or some college boys' math advantage over girls continuously grows across childhood. At the last two assessments, boys also have a higher mean math score than girls whose mothers have no qualifications. However, the difference is not statistically different from zero at the $5 \%$ level. The same is true for children of mothers who graduated from college. In sum, the results are consistent with the expected pattern of boys' math advantage increasing with maternal education except for the group with the most highly educated mothers. The variation in gender differences (or lack thereof) is mostly driven by a larger variation in boys' mean scores (see upper part of Figure 1). We find a very similar pattern in the ECLS-K data (see Figure D1 in the Appendix). 

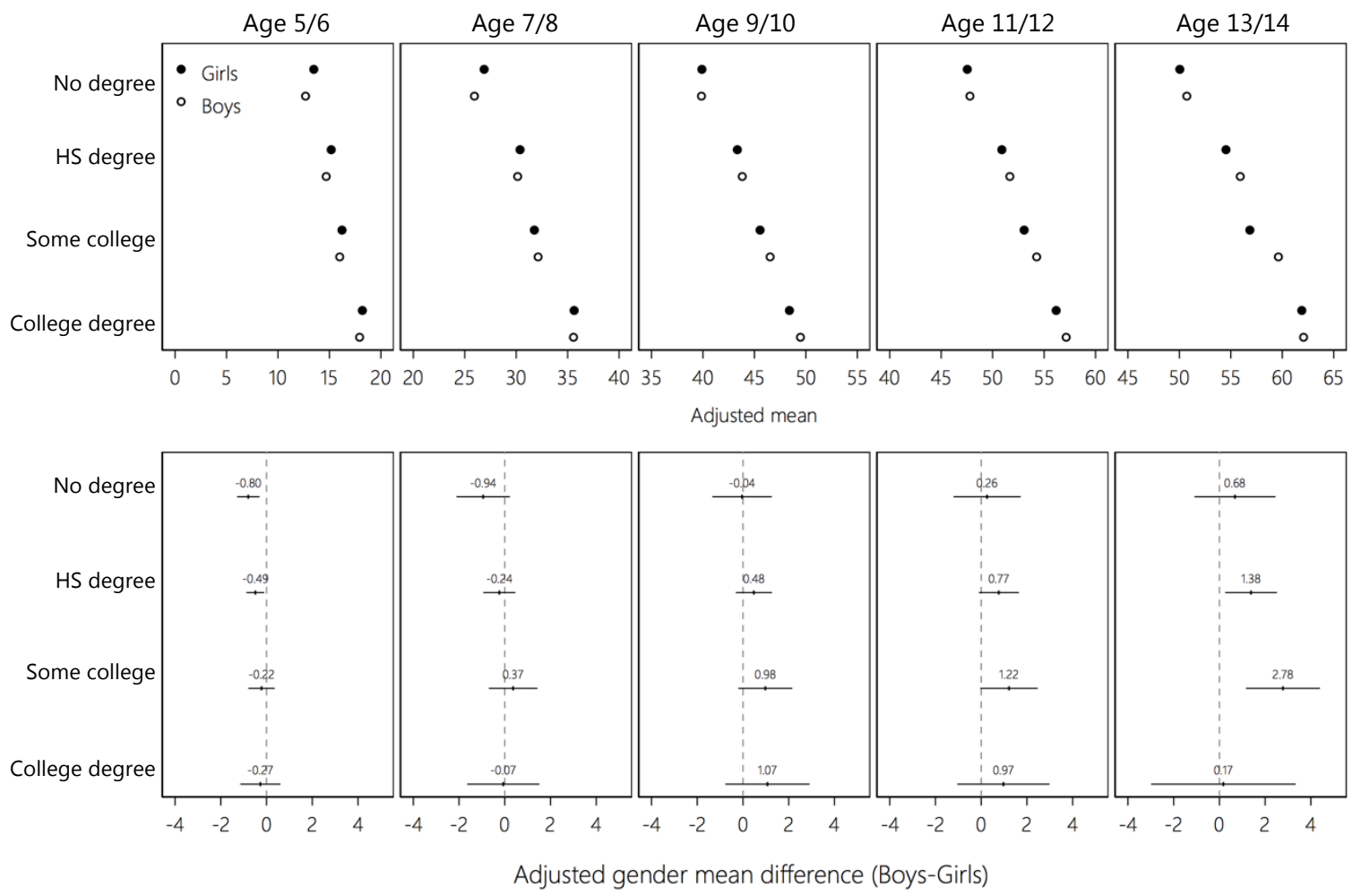

Figure 2. Gender-specific adjusted mean math score and adjusted gender mean difference (with $95 \%$ confidence interval) by maternal education and age at assessment Note: HS = Highschool; Estimates derived from OLS regression model described by equation 1 .

As our model allows for heterogeneity in the intersection of gender and maternal education by race, we can further stratify the analyses. The results show very similar patterns for Hispanics and Others with Blacks deviating from the average pattern seen before (see Figure C1 in the Appendix). While boys' advantage in the group with the most highly educated mothers appears to decline at the last assessment for Hispanics and Others (consistent with the overall pattern), Black boys in this group face a disadvantage at all assessments, and this disadvantage is growing over time. Because of the small sample size of this group, there is a high degree of statistical uncertainty attached to these estimates as indicated by the large confidence intervals. A 
comparison of the estimates with those from the ECLS-K (see Figure D2 in the Appendix), however, indicates similar results, thus suggesting that they are not entirely the result of random sampling error. Comparing the gender-specific averages for Black children with highly educated mothers with those of the two other racial groups with similarly educated mothers shows that it is the Black boys falling behind rather than particularly high-performing Black girls explaining this result.
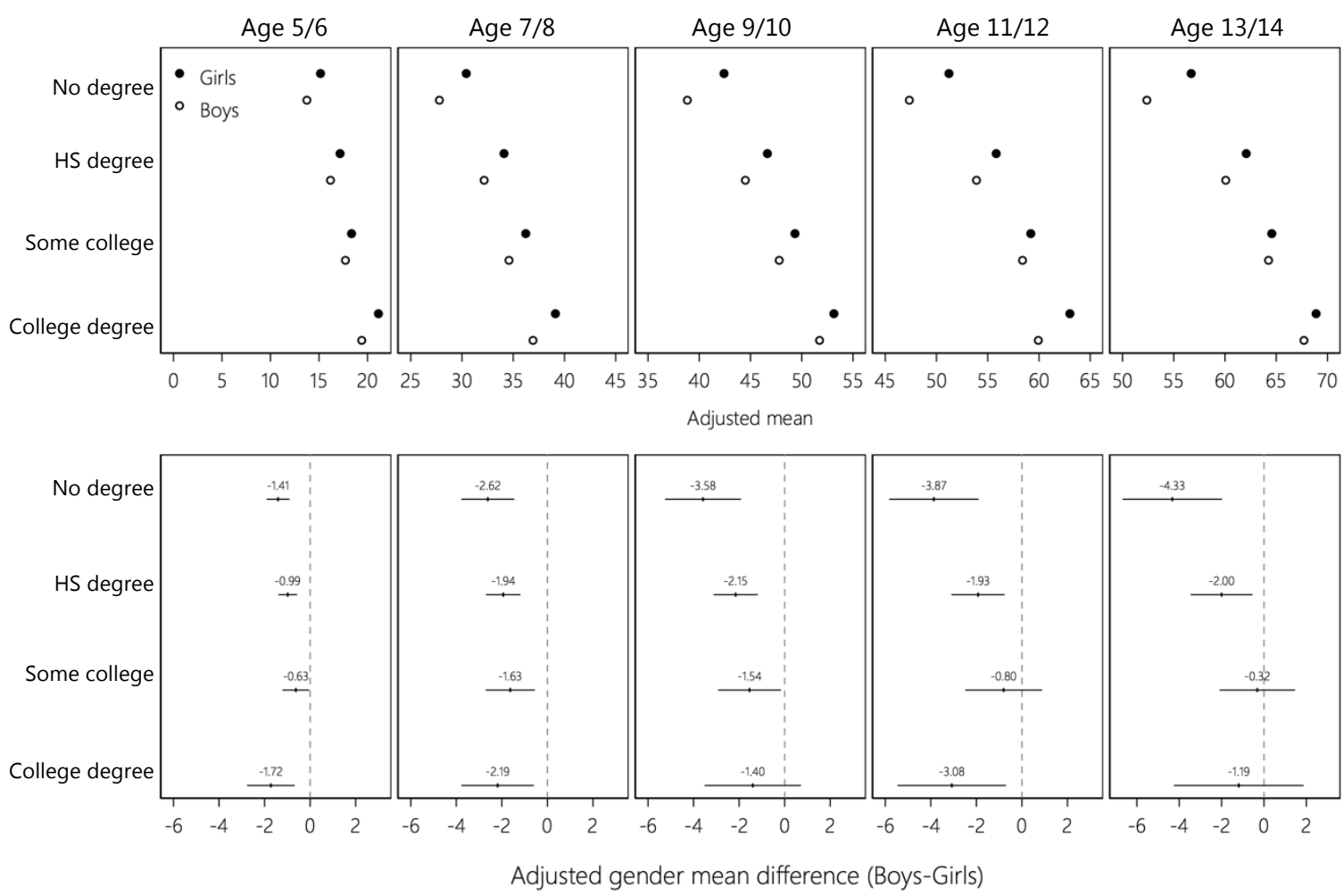

Figure 3. Gender-specific adjusted mean reading recognition score and adjusted gender mean difference (with 95\% confidence interval) by maternal education and age at assessment Note: $\mathrm{HS}=$ Highschool; Estimates derived from OLS regression model described by equation 1.

We summarized the results for reading recognition in Figure 3. Across the assessments, we see a growing disadvantage for boys, particularly in the group of children whose mothers did not graduate from high school. Smaller disadvantages arise within the groups of children with 
mothers who have completed high school or who have attended college. With a somewhat larger disadvantage for boys at later assessments, children whose mothers have attained a college degree are again the only group who do not conform entirely to our theoretical expectations. In the ECLS-K, however, the results for gender differences in reading by maternal education are also more consistent with the theoretical expectations in later assessments (see Figure D3 in the Appendix). In sum, boys' disadvantages in reading tend to be more substantial, the smaller the amount of education of the mother is.

In the analyses stratified by race (see Figure $\mathrm{C} 2$ in the Appendix), these patterns are less clear, especially for Black children. As with math, we see a significant reading disadvantage for Black boys whose mothers are highly educated in both the NLSY and the ECLS-K data (see Figure D4 in the Appendix). For Hispanics and Others, we see the largest disadvantage for boys among children whose mothers have not completed high school, which is in line with the theoretical expectations.

Turning to children's behavior, Figure 4 shows the results for externalizing problems. In line with the theoretical expectations, we find a disadvantage for boys across the first four assessments, which is larger the lower the education of the mother. Among the group of children with the most highly educated mothers, however, gender differences are statistically insignificant at any age. At the last assessment, the gender difference in externalizing problems is statistically significant for none of the educational groups. The smaller gap in externalizing problems between boys and girls at the last assessment (age 12/13) is mainly driven by a decline in boys' externalizing problems, particularly in the group of children whose mothers have not completed college (see the upper part of the figure). Overall, these patterns are similar when stratifying the analyses by race (see Figure C3 in the Appendix). In sum, our analyses show that boys' 
disadvantage in externalizing behavior problems is particularly pronounced among children whose mothers have no qualifications (albeit less so at the last assessment).
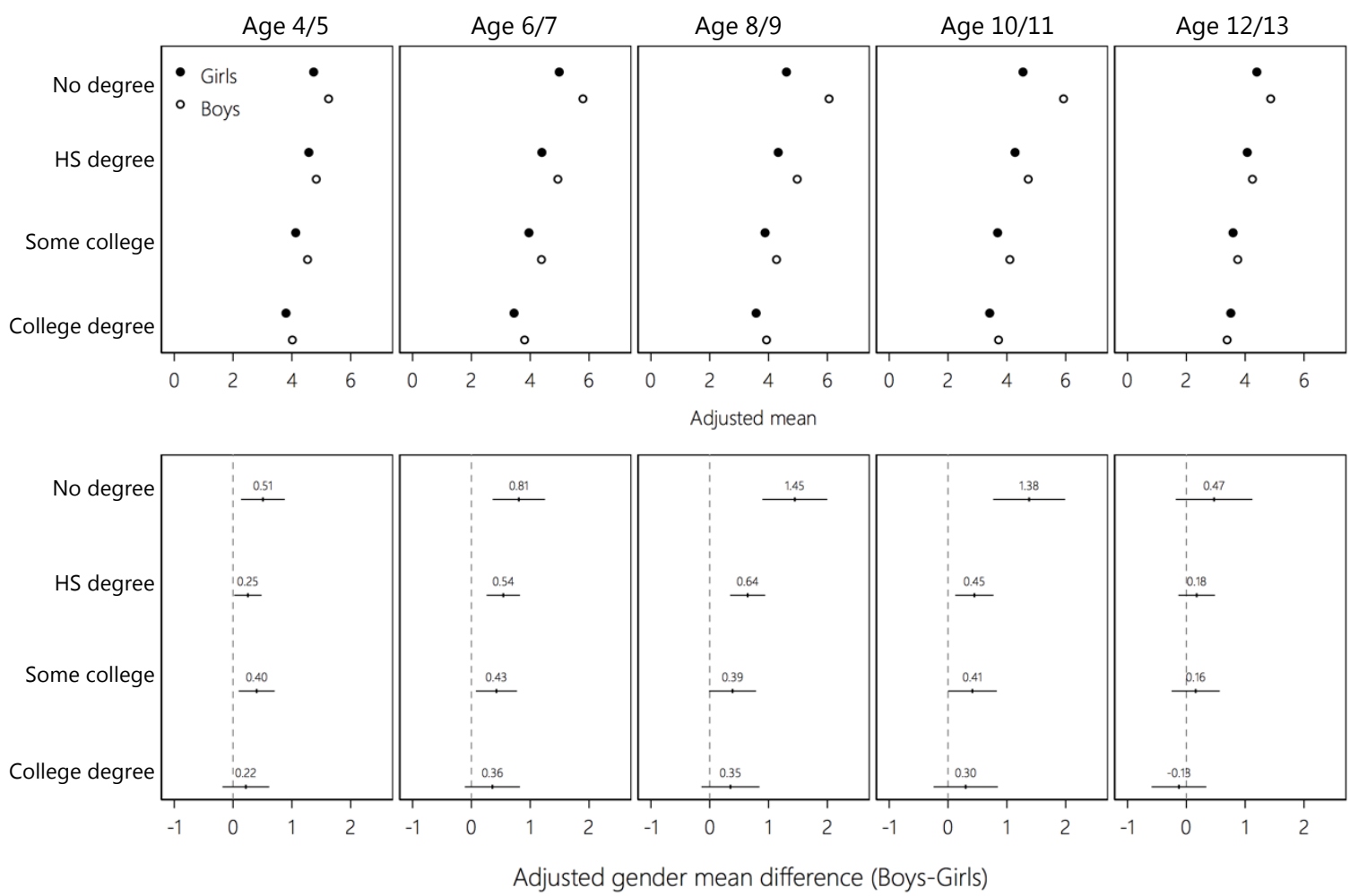

Figure 4. Gender-specific adjusted mean externalizing problems score and adjusted gender mean difference (with 95\% confidence interval) by maternal education and age at assessment Note: HS = Highschool; Estimates derived from OLS regression model described by equation 1 .

For internalizing problems, Figure 5 largely confirms the earlier results on overall gender differences by indicating only few group-specific gender differences that are statistically significant at the 5\% level. While the mean internalizing problems score is generally higher for children whose mothers have less education, this pattern is very similar for boys and girls compared to the other measures under study. This is also true when stratifying the analyses by race (see Figure C4 in the Appendix). 

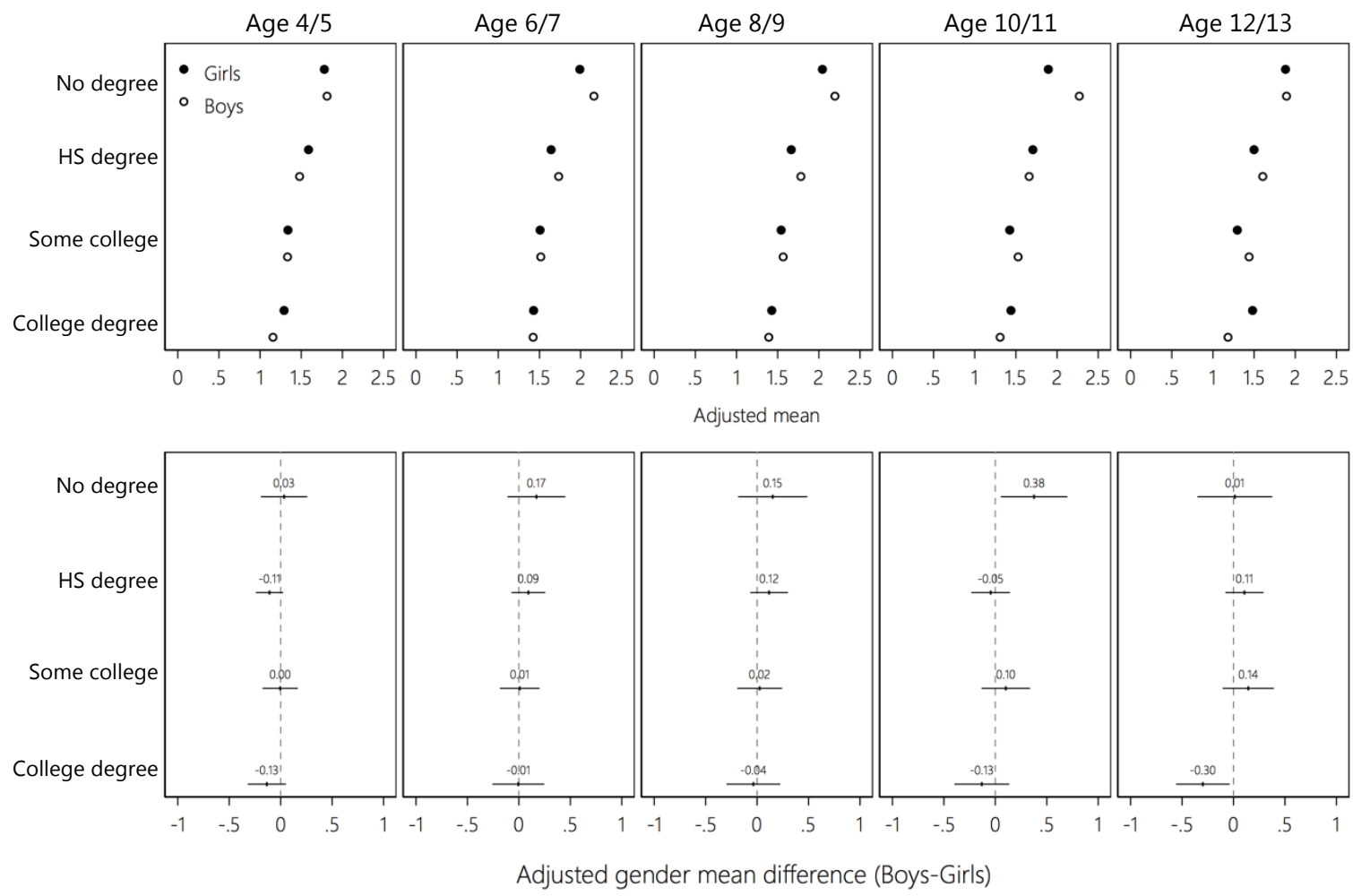

Figure 5. Gender-specific adjusted mean internalizing problems score and adjusted gender mean difference (with $95 \%$ confidence interval) by maternal education and age at assessment Note: $\mathrm{HS}=$ Highschool; Estimates derived from OLS regression model described by equation 1.

\section{Gender differences by family structure}

In the following, we present gender-specific means and gender differences in means of the different outcome scores by family structure at birth. We derive these estimates from a model shown in equation 1 and additionally including two-way and three-way interaction terms of family structure with the child's gender and race. That is the model allows gender differences by family structure to vary across race while simultaneously controlling for (race-specific) gender differences by parental education. 


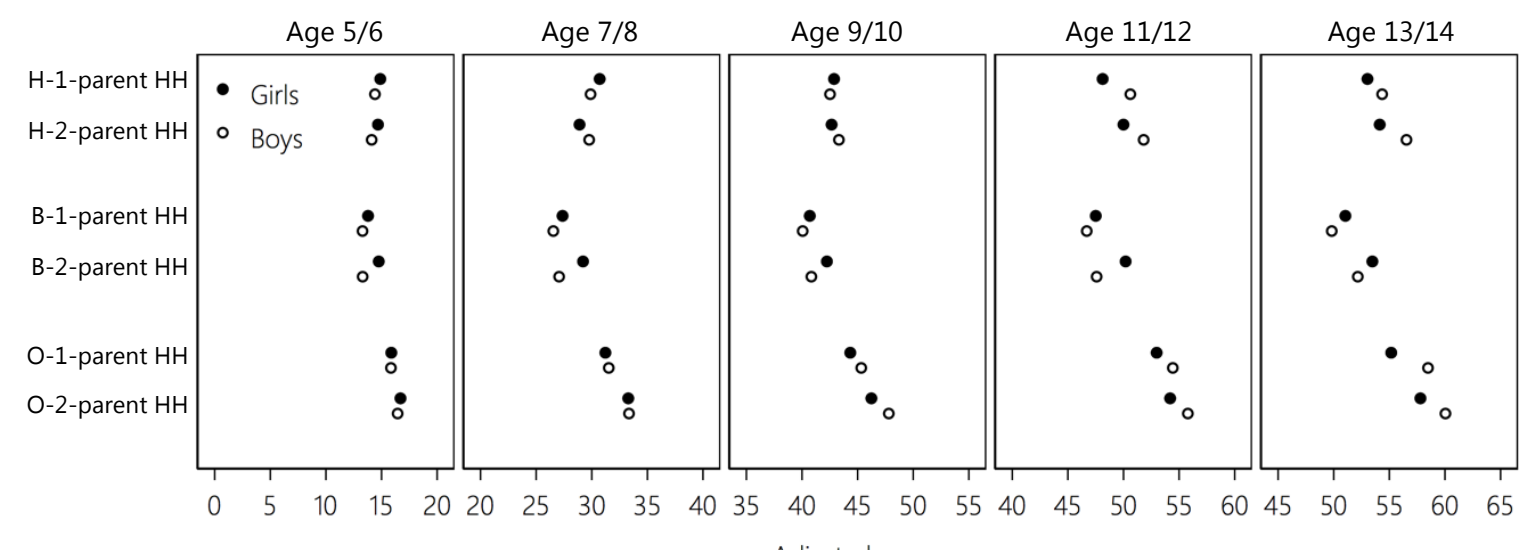

Adjusted mean

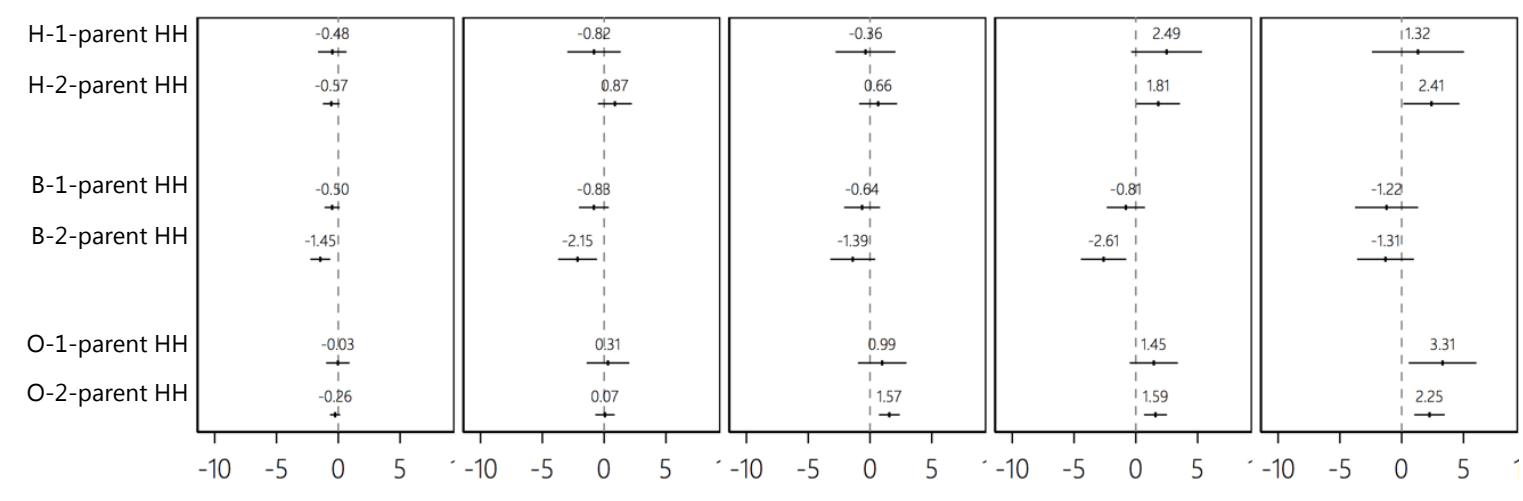

Adjusted gender mean difference (Boys-Girls)

Figure 6. Gender-specific adjusted mean math score and adjusted gender mean difference (with $95 \%$ confidence interval) by family type, race and age at assessment Note: $\mathrm{H}=$ Hispanic; $\mathrm{B}=\mathrm{Black} ; \mathrm{O}=$ Other; $\mathrm{HH}=$ Household; Estimates derived from OLS regression model described by equation 1 .

Figures 6 and 7 show the results for the math and reading scores. On average, children born into two-parent households perform better on math and reading scores than those born into one-parent households. However, there is no clear pattern of variation in gender differences between children born into one-parent households and those born into two-parent households for any of the three racial groups. This is also evident in the ECLS-K data (see Figures D5 and D6 in the Appendix). While children born into one-parent households display more externalizing and 
internalizing behavioral problems than children in two-parent households, there are, likewise, no clear differences in gender disparities by family structure (see Figure C5 and C6 in the Appendix).
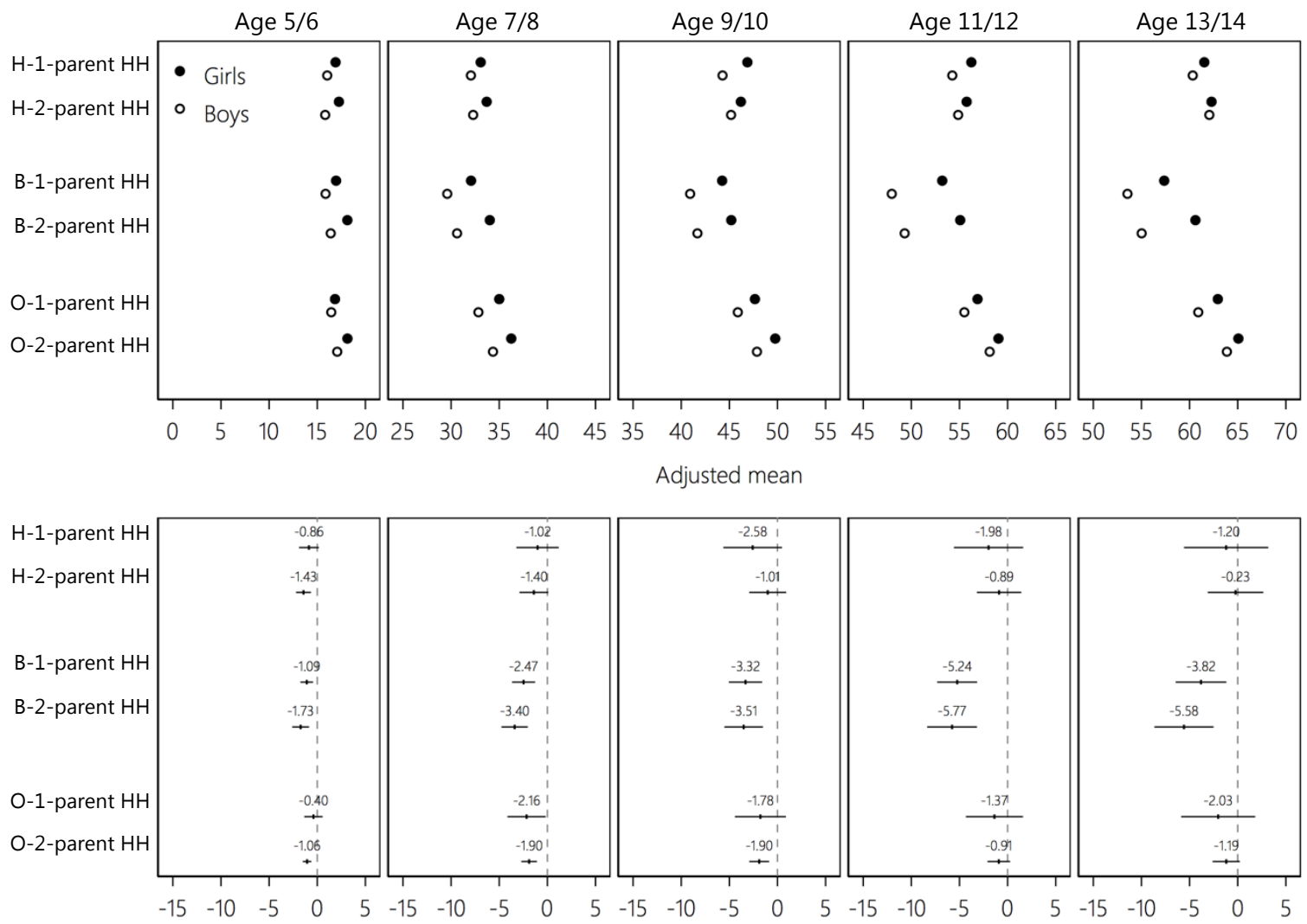

Adjusted gender mean difference (Boys-Girls)

Figure 7. Gender-specific adjusted mean reading recognition score and adjusted gender mean difference (with 95\% confidence interval) by family type, race and age at assessment Note: $\mathrm{H}=$ Hispanic; $\mathrm{B}=$ Black; $\mathrm{O}=$ Other; $\mathrm{HH}=$ Household; Estimates derived from OLS regression model described by equation 1 .

\section{DISCUSSION}

In this study, we explored the "boy crisis" in context by investigating whether gender differences in academic achievement and behavior problems vary across the family environment. We 
expected that gender differences are stronger among children growing up in disadvantaged family circumstances than they are among children from advantaged backgrounds. Our initial results confirm the previous literature in showing that boys have disadvantages in reading and greater externalizing behavior problems than girls, while they achieve, on average, higher scores in math than their female counterparts. While boys have disadvantages in reading throughout childhood until adolescence, their advantage in math only emerges around age 9/10. This result is consistent with previous evidence that girls are disadvantaged in math at later ages (Cameron et al. 2015; Cornwell et al. 2014; Fryer and Levitt 2010). Boys' disadvantage in externalizing behavior problems disappears around age 12/13, but it may nonetheless leave a mark on boys' long-term educational trajectories due to the disruptions in learning/schooling at the time. In line with previous literature (e.g. Downey et al. 2019), gender differences in internalizing behavior problems are rather small.

Our main results provided evidence that gender differences across childhood in academic achievement and externalizing behavior problems vary by maternal education but not by family structure at birth. They suggest that boys' advantage in math grows and their disadvantages in reading and externalizing behavior problems decline as mothers' education increases. The growing advantage across mother's education confirms previous findings showing that boys have an advantage at the top of the distribution as children from higher educational backgrounds are more often found at the top (e.g., Ellison and Swanson 2010; Entwisle et al. 1994). Notably, Black children considerably deviate from the patterns observed for other children. For both math and reading, we found unusually large disadvantages for Black boys whose mothers completed college. While Black girls from advantaged educational backgrounds perform much better in 
reading and math than Black girls from disadvantaged backgrounds, Black boys whose mothers have a college degree cannot use this educational background much to their benefit.

Overall, the variation in gender gaps by maternal education is, however, mainly driven by differences in the group-specific mean scores for boys. Boys whose mothers have less education substantially lag behind their peers from advantaged educational backgrounds in their academic achievement. They also have stronger externalizing behavior problems than their advantaged counterparts. The differences in academic achievement and behavior problems by maternal education are less pronounced among girls. While we did not find these patterns for family structure, it partly confirms our expectation that boys are more susceptible to a disadvantaged family environment than girls. These results are in line with previous research suggesting that boys' disadvantage in reading compared to girls only applies to families from lower socioeconomic backgrounds (Entwisle et al. 2007). Boys' advantage in mathematics over girls was also found to be largest among students whose parents are highly educated (Penner and Paret 2008).

The observed group differences in gender gaps by maternal education are in most cases statistically insignificant, and confidence intervals are often wide. However, the consistency of these observed patterns across outcomes and two different datasets (NLSY-CYA and ECLS-K) suggests that they may not merely be the result of random error. Our replication efforts, in combination with previous findings, give us confidence that the observed patterns in the data accurately represent the interdependent impact of children's gender and mother's education on their academic achievement and behavior.

Although we did not test any mediating pathways, our findings can provide some insights into the mechanisms underlying gender differences in academic achievement and behavior 
during childhood. Most importantly, the heterogeneous gender differences by maternal education highlight the importance of social aspects like cultural norms or gender-specific parenting for explaining the specific advantages and disadvantages of boys and girls. It is unlikely that any biological differences between boys and girls would vary between socioeconomic groups and thus explain differences in achievement and behavior. At the same time, our findings illustrate that not all aspects of the family environment are equally important in shaping gender differences across childhood. The fact that we did not find systematic differences in gender gaps between children born into one-parent and two-parent households speaks against the argument that boys are naturally more susceptible to adverse family conditions than girls (Autor et al. 2019). If this were the case, we would also see more significant relative disadvantages of boys in single-parent households. Our findings instead suggest that cultural norms (as held by different educational groups) are more important than family resources and the presence of (male) role models (as captured by family structure after adjustment for maternal education) in explaining the heterogeneity of gender-typical achievement and behavior across family circumstances.

Overall, this study affirms the importance of an intersectional perspective of gender differences. Unitary and multiple category approaches to inequality in academic achievement and behavior do not adequately capture children's lived experiences. If we want to understand the origins of the gender gap in educational outcomes, we must investigate the family circumstances under which these gender inequalities arise and ask to what extent they contribute to gender differences in childhood and adolescence. It is therefore vital to focus on how gender differences in academic achievement are "embedded in and shaped by hierarchical structures of difference and inequality" (Penner and Paret 2008: 251). 
Future research may investigate the reasons for heterogeneous gender differences across mothers' educational background more directly. In this regard, cross-national research on gender differences across childhood comparing countries that differ in gender norms may provide further analytical leverage. It may also be worthwhile to investigate whether these gender differences across socioeconomic groups are already visible during earlier ages and to test whether gender differences in children's development vary across other family circumstances such as mother's employment status or sibship size. 


\section{NOTES}

${ }^{1}$ Differential investments in boys and girls by family background is in line with the Trivers-Willard hypothesis (Trivers and Willard 1973). This hypothesis suggests that high-status parents invest more in sons, whereas lowstatus parents invest more in their daughters. Evidence for this hypothesis exists in relation to educational outcomes (Hopcroft 2005; Hopcroft and Martin 2014), but direct tests of educational investments provide mixed results (Freese and Powell 1999; Hopcroft and Martin 2016).

${ }^{2}$ The sample of disadvantaged non-Hispanics/non-Blacks was discontinued after 1990 due to budget constraints. This discontinuation was similar to a sample of 1,280 men and women serving in the US military after 1984 .

${ }^{3}$ See Appendix A for a detailed overview of the number of cases over time and a comparison of the case numbers after the different sample restrictions.

${ }^{4}$ Guttmannova, Szanyi, and Cali (2008) demonstrated cross-ethnic and longitudinal measurement invariance for these scales to be superior to those of the respective scales provided in the NLSY-CYA, which were derived by Parcel and Menaghan (1988).

${ }^{5}$ The internalizing scale for children aged four to eleven consists of seven items and six items for children over the age of eleven. The externalizing score is based on nine items for children aged four to five, ten items for children aged six to eleven, and eight items for children aged twelve and older. 


\section{REFERENCES}

Alexander, Karl L. and Bruce K. Eckland. 1974. "Sex Differences in the Educational Attainment Process." American Sociological Review 39(5):668-82.

Arnett, Anne B., Bruce F. Pennington, Erik G. Willcutt, John C. Defries, and Richard K. Olson. 2015. "Sex Differences in ADHD Symptom Severity." Journal of Child Psychology and Psychiatry and Allied Disciplines 56(6):632-39.

Autor, David, David Figlio, K. Karbownik, Jeffrey Roth, and Melanie Wasserman. 2019. "Family Disadvantage and the Gender Gap in Behavioral and Educational Outcomes." American Economic Journal: Applied Economics 11(3):338-381.

Baker, Michael and Kevin Milligan. 2016. "Boy-Girl Differences in Parental Time Investments: Evidence from Three Countries." Journal of Human Capital 10(4):399-441.

Barnett, Lynn A. 2018. "The Education of Playful Boys: Class Clowns in the Classroom." Frontiers in Psychology 9: 232.

Bauer, Greta R. 2014. "Incorporating Intersectionality Theory into Population Health Research Methodology: Challenges and the Potential to Advance Health Equity.” Social Science and Medicine 110:10-17.

Beilock, Sian L., Elizabeth A. Gunderson, Gerardo Ramirez, and Susan C. Levine. 2010. “Female Teachers' Math Anxiety Affects Girls' Math Achievement." Proceedings of the National Academy of Sciences 107(5): 1860-1863.

Bertrand, Marianne and Jessica Pan. 2013. "The Trouble with Boys: Social Influences and the Gender Gap in Disruptive Behavior." American Economic Journal: Applied Economics $5(1): 32-64$.

Bodovski, Katerina and Min-Jong Youn. 2011. “The Long Term Effects of Early Acquired Skills 
and Behaviors on Young Children's Achievement in Literacy and Mathematics.” Journal of Early Childhood Research 9(1):4-19.

Bolzendahl, Catherine I. and Daniel J. Myers. 2007. "Feminist Attitudes and Support for Gender Equality: Opinion Change in Women and Men, 1974-1998." Social Forces 83(2):759-789.

Bozick, Robert and Stefanie DeLuca. 2005. "Better Late Than Never? Delayed Enrollment in the High School to College Transition." Social Forces 84(1):531-54.

Bradley, Robert H. and Robert F. Corwyn. 2002. "Socioeconomic Status and Child Development." Annual Review of Psychology 53(1):371-399.

Brewster, Karin L. and Irene Padavic. 2000. "Change in Gender-Ideology, 1977-1996: The Contributions of Intracohort Change and Population Turnover." Journal of Marriage and Family 62(2):477-487.

Brooks, Clem and Catherine Bolzendahl. 2004. "The Transformation of US Gender Role Attitudes: Cohort Replacement, Social-Structural Change, and Ideological Learning.” Social Science Research 33(1):106-133.

Buchmann, Claudia and Thomas A. DiPrete. 2006. "The Growing Female Advantage in College Completion: The Role of Family Background and Academic Achievement." American Sociological Review 71(4):515-41.

Buchmann, Claudia, Thomas A. DiPrete, and Anne McDaniel. 2008. "Gender Inequalities in Education." Annual Review of Sociology 34(1):319-37.

Cameron, Claire E., Kevin J. Grimm, Joel S. Steele, Laura Castro-Schilo, and David W. Grissmer. 2015. "Nonlinear Gompertz Curve Models of Achievement Gaps in Mathematics and Reading.” Journal of Educational Psychology 107(3):789-804.

Catsambis, Sophia. 1994. "The Path to Math: Gender and Racial-Ethnic Differences in 
Mathematics Participation from Middle School to High School." Sociology of Education 67(3):199-215.

Caughy, Margaret O. Brie., Tatiana Nogueira Peredo, Margaret Tresch Owen, and Britain Mills. 2016. "Gender Differences in the Relation between Mothering Behaviors and ChildBehavior Problems among Hispanic Preschoolers." Developmental Psychology 52(4):59298.

Cech, Erin, Brian Rubineau, Susan Silbey, and Caroll Seron. 2011. "Professional Role Confidence and Gendered Persistence in Engineering." American Sociological Review 76(5): 641-666.

Ceci, S. J. and W. M. Williams. 2011. 'Understanding Current Causes of Women's Underrepresentation in Science." Proceedings of the National Academy of Sciences 108(8):3157-62.

Ceci, Stephen J., Donna K. Ginther, Shulamit Kahn, and Wendy M. Williams. 2014. "Women in Academic Science: A Changing Landscape.” Psychological Science in the Public Interest $15(3): 75-141$.

Ceci, Stephen J., Wendy M. Williams, and Susan M. Barnett. 2009. 'Women's Underrepresentation in Science: Sociocultural and Biological Considerations." Psychological Bulletin 135(2):218-61.

Chatterji, Madhabi. 2006. "Reading Achievement Gaps, Correlates, and Moderators of Early Reading Achievement: Evidence from the Early Childhood Longitudinal Study (ECLS) Kindergarten to First Grade Sample.” Journal of Educational Psychology 98(3):489-507.

Cheadle, Jacob E. and Paul R. Amato. 2010. “A Quantitative Assessment of Lareau's Qualitative Conclusions About Class, Race, and Parenting." Journal of Family Issues 32(5):679-706. 
Chmielewski, Anna K. 2019. "The Global Increase in the Socioeconomic Achievement Gap, 1964 to 2015." American Sociological Review 84(3):517-544.

Cimpian, Joseph R., Sarah T. Lubienski, Jennifer D. Timmer, Martha B. Makowski, and Emily K. Miller. 2016. "Have Gender Gaps in Math Closed? Achievement, Teacher Perceptions, and Learning Behaviors Across Two ECLS-K Cohorts." AERA Open 2(4):233285841667361.

Conger, Dylan and Mark C. Long. 2010. "Why Are Men Falling behind? Gender Gaps in College Performance and Persistence." Annals of the American Academy of Political and Social Science 627(1):184-214.

Cornwell, Christopher et al. 2014. "Noncognitive Skills and the Gender Disparities in Test Scores and Teacher Assessments: Evidence from Primary School." Journal of Human Resources 48(1):236-64.

Crowley, Kevin, Maureen A. Callanan, Harriet R. Tenenbaum, and Elizabeth Allen. 2001. "Parents Explain More Often To Boys Than To Girls During Shared Scientific Thinking." Psychological Science 12(3):258-61.

Cvencek, Dario, Andrew N. Meltzoff, and Anthony G. Greenwald. 2011. "Math-Gender Stereotypes in Elementary School Children." Child Development 82(3):766-79.

Dee, Thomas S. 2006. “The Why Chromosome: How a Teacher's Gender Affects Boys and Girls." Education Next 6(4):68.

Dee, Thomas S. 2005. “A Teacher like Me: Does Race, Ethnicity, or Gender Matter?” The American Economic Review 95(2):158-65.

DiPrete, Thomas A. and Jennifer L. Jennings. 2012. "Social and Behavioral Skills and the Gender Gap in Early Educational Achievement." Social Science Research 41:1-15. 
Downey, Douglas B. and Anastasia Vogt Yuan. 2005. "Sex Differences in School Performance during High School: Puzzling Patterns and Possible Explanations.” The Sociological Quarterly 46(2):299-321.

Downey, Douglas B., Joseph Workman, and Paul von Hippel 2019. Socioeconomic, Ethnic, Racial, and Gender Gaps in Children's Social/Behavioral Skills: Do They Grow Faster in School or out? Sociological Science 6:446-466.

Doyle, Randi A. and Daniel Voyer. 2016. "Stereotype Manipulation Effects on Math and Spatial Test Performance: A Meta-Analysis.” Learning and Individual Differences 47:103-16.

Driessen, Geert. 2007. "The Feminization of Primary Education: Effects of Teachers' Sex on Pupil Achievement, Attitudes and Behaviour." Review of Education 53(2):183-203.

Dumais, Susan A. 2002. "Cultural Capital, Gender, and School Success: The Role of Habitus." Sociology of Education 75(1):44-68.

Duncan, Greg J. and Katherine Magnuson. 2011. The Nature and Impact of Early Achievement Skills, Attention Skills, and Behavior Problems", in Greg J. Duncan and Richard J. Murnane (eds.), Whither Opportunity: Rising Inequality, Schools, and Children's Life Chances, New York: Russell Sage, 2011, pp. 47-69

Dunn, L. M. and F. C. Markwardt. 1970. Peabody Individual Achievement Test Manual. Circle Pines, MN: American Guidance Service.

Eccles, Jacquelynne S., Janis E. Jacobs, and Rena D. Harold. 1990. “Gender Role Stereotypes, Expectancy Effects, and Parents' Socialization of Gender Differences." Journal of Social Issues 46(2):183-201.

Ehrenberg, Ronald G., Daniel G. Goldhaber, and Dominic J. Brewer. 1995. “Do Teachers’ Race, Gender, and Ethnicity Matter? Evidence from the National Educational Longitudinal Study 
of 1988 ." Industrial and Labor Relations Review 48(3):547-61.

Ehrtmann, Lisa and Ilka Wolter. 2018. "The Impact of Students' Gender-Role Orientation on Competence Development in Mathematics and Reading in Secondary School.” Learning and Individual Differences 61:256-64.

Ellison, Glenn and Ashley Swanson. 2010. "The Gender Gap in Secondary School Mathematics at High Achievement Levels: Evidence from the American Mathematics Competitions." Journal of Economic Perspectives 24(2):109-28.

Else-Quest, Nicole M., Janet Shibley Hyde, H. Hill Goldsmith, and Carol A. Van Hulle. 2006. "Gender Differences in Temperament: A Meta-Analysis." Psychological Bulletin 132(1):33-72.

Else-Quest, Nicole M., Concetta C. Mineo, and Ashley Higgins. 2013. "Math and Science Attitudes and Achievement at the Intersection of Gender and Ethnicity." Psychology of Women Quarterly 37(3):293-309.

Entwisle, Doris R., Karl L. Alexander, and Linda S. Olson. 2007. "Early Schooling: The Handicap of Being Poor and Male." Sociology of Education 80(2):114-38.

Entwisle, Doris R., Karl L. Alexander, and Linda S. Olson. 1994. "The Gender Gap in Math : Its Possible Origins in Neighborhood Effects." American Sociological Review 59(6):822-38.

Evans, Ruth and Louise Holt. 2011. "Diverse Spaces of Childhood and Youth: Gender and Other Socio-Cultural Differences." Children's Geographies 9(3-4):277-84.

Fan, Xitao, Michael Chen, and Audrey R. Matsumoto. 1997. "Gender Differences in Mathematics Achievement: Findings from the National Education Longitudinal Study of 1988." The Journal of Experimental Education 65(3):229-42.

Fiorini, Mario and Michael P. Keane. 2014. "How the Allocation of Children's Time Affects 
Cognitive and Noncognitive Development." Journal of Labor Economics 32(4):787-836.

Fortin, Nicole M., Philip Oreopoulos, and Shelley Phipps. 2015. "Leaving Boys Behind: Gender Disparities in High Academic Achievement." Journal of Human Resources 50(3):549-79.

Freese, Jeremy and Brian Powell. 1999. "Sociobiology, Status, and Parental Investment in Sons and Daughters: Testing the Trivers-Willard Hypothesis." American Journal of Sociology 104(6):1704-43.

Fryer, Roland G. and Steven D. Levitt. 2010. "An Empirical Analysis of the Gender Gap in Mathematics." American Economic Journal: Applied Economics 2(2):210-40.

Furnham, Adrian, Emma Reeves, and Salima Budhani. 2002. "Parents Think Their Sons Are Brighter than Their Daughters: Sex Differences in Parental Self-Estimations and Estimations of Their Children's Multiple Intelligences." Journal of Genetic Psychology 163(1):24-39.

Ganley, Colleen M. et al. 2013. "An Examination of Stereotype Threat Effects on Girls' Mathematics Performance.” Developmental Psychology 49(10):1886-97.

Gentrup, Sarah and Camilla Rjosk. 2018. "Pygmalion and the Gender Gap: Do Teacher Expectations Contribute to Differences in Achievement between Boys and Girls at the Beginning of Schooling ?" Educational Research and Evaluation 24(3-5): 295-323.

Gibbs, B. G. 2010. "Reversing Fortunes or Content Change? Gender Gaps in Math-Related Skill throughout Childhood." Social Science Research 39(4):540-69.

Goldin, Claudia, Lawrence F. Katz, and Ilyana Kuziemko. 2006. "The Homecoming of American College Women: The Reversal of the College Gender Gap.” Journal of Economic Perspectives 20(4):133-56.

Gunderson, Elizabeth A., Gerardo Ramirez, Susan C. Levine, and Sian L. Beilock. 2012. "The 
Role of Parents and Teachers in the Development of Gender-Related Math Attitudes." Sex Roles 66(3-4):153-66.

Guttmannova, Katarina, Jason M. Szanyi, and Philip W. Cali. 2008. "Internalizing and Externalizing Behavior Problem Scores." Educational and Psychological Measurement 68(4):676-94.

Halpern, Diane F. (2011) Sex Differences in Cognitive Abilities Fourth Edition, New York:

Psychology Press.

Hancock, Ange Marie. 2007. “When Multiplication Doesn't Equal Quick Addition: Examining Intersectionality as a Research Paradigm.” Perspectives on Politics 5(1):63-79.

van Hek, Margriet, Claudia Buchmann, and Gerbert Kraaykamp. 2019. "Educational Systems and Gender Differences in Reading: A Comparative Multilevel Analysis." European Sociological Review 35(2):169-86.

van Hek, Margriet, Gerbert Kraaykamp, and Ben Pelzer. 2018. "Do Schools Affect Girls' and Boys' Reading Performance Differently? A Multilevel Study on the Gendered Effects of School Resources and School Practices." School Effectiveness and School Improvement 29(1):1-21.

Henry, Daphne A., Elizabeth Votruba-Drzal, and Portia Miller. 2019. "Child development at the intersection of race and SES: An overview." Advances in child development and behavior. 57.:1-25.

Heyder, Anke and Ursula Kessels. 2013. "Is School Feminine? Implicit Gender Stereotyping of School as a Predictor of Academic Achievement.”Sex Roles 69(11-12):605-17.

Hopcroft, Rosemary L. 2005. "Parental Status and Differential Investment in Sons and Daughters: Trivers-Willard Revisited.” Social Forces 83(3):1111-36. 
Hopcroft, Rosemary L. and David O. Martin. 2016. "Parental Investments and Educational Outcomes: Trivers-Willard in the U.S." Frontiers in Sociology 1:3.

Hopcroft, Rosemary L. and David O. Martin. 2014. "The Primary Parental Investment in Children in the Contemporary USA Is Education: Testing the Trivers-Willard Hypothesis of Parental Investment." Human Nature 25(2): 235-250.

Hsin, Amy. 2018. "Hegemonic Gender Norms and the Gender Gap in Achievement: The Case of Asian Americans.” Sociological Science 5:752-74.

Husain, Muna and Daniel L. Millimet. 2009. “The Mythical 'Boy Crisis'?” Economics of Education Review 28(1):38-48.

Hyde, Janet S., Sara M. Lindberg, Marcia C. Linn, Amy B. Ellis, and Caroline C. Williams. 2008. “Gender Similarities in Math Performance.” Science 321(5888):494-95.

Jacob, Brian A. 2002. “Where the Boys Aren't: Non-Cognitive Skills, Returns to School and the Gender Gap in Higher Education.” Economics of Education Review 21(6):589-98.

Kowaleski-Jones, Lori and Greg J. Duncan. 1999. "The Structure of Achievement and Behavior across Middle Childhood." Child Development 70(4):930-43.

Lachance, Jennifer A. and Michèle M. Mazzocco. 2006. “A Longitudinal Analysis of Sex Differences in Math and Spatial Skills in Primary School Age Children." Learning and Individual Differences 16(3):195-216.

Lahey, Benjamin B. et al. 2006. "Testing Descriptive Hypotheses Regarding Sex Differences in the Development of Conduct Problems and Delinquency." Journal of Abnormal Child Psychology 34(5):737-55.

Lareau, Anette. 2011. Unequal Childhoods: Class, Race, and Family Life. Berkeley: University of California Press. 
Leahey, E. and G. Guo. 2001. “Gender Differences in Mathematical Trajectories.” Social Forces 80(2):713-32.

Leaper, Campbell, Kristin J. Anderson, and Paul Sanders. 1998. "Moderators of Gender Effects on Parents' Talk to Their Children: A Meta-Analysis.” Developmental Psychology 34(1):327.

Lee, Kyunghee. 2010. "Do Early Academic Achievement and Behavior Problems Predict LongTerm Effects among Head Start Children?" Children and Youth Services Review 32(12):1690-1703.

Legewie, Joscha and Thomas A. DiPrete. 2012. "School Context and the Gender Gap in Educational Achievement." American Sociological Review 77(3):463-85.

Legewie, Joscha and Thomas A. DiPrete. 2014. "The High School Environment and the Gender Gap in Science and Engineering." Sociology of Education 87(4):259-80.

Li, Qing. 1999. "Teachers' Beliefs and Gender in Differences in Mathematics: A Review." Educational Research 41(1):63-76.

Lundberg, Shelly. 2017. "Father Absence and the Educational Gender Gap." IZA Discussion Paper No. 10814.

Lundberg, Shelly. 2005. "Sons, Daughters, and Parental Behaviour." Oxford Review of Economic Policy 21(3):340-56.

Martin, Karin A. 1998. "Becoming a Gendered Body: Practices of Preschools." American Sociological Review: 494-511.

McHale, Susan M., Ann C. Crouter, and Corinna J. Tucker. 1999. "Family Context and Gender Role Socialization in Middle Childhood: Comparing Girls to Boys and Sisters to Brothers." Child Development 70(4):990-1004. 
McIntosh, Kent, Wendy M. Reinke, Joanna L. Kelm, and Carol A. Sadler. 2013. “Gender Differences in Reading Skill and Problem Behavior in Elementary School.” Journal of Positive Behavior Interventions 15(1):51-60.

McLeod, Jane D. and Karen Kaiser. 2004. "Childhood Emotional and Behavioural Problems and Educational Attainment." American Sociological Review 69:636-58.

Morgan, Paul L., George Farkas, and Jacob Hibel. 2008. "Matthew Effects for Whom?" Learning Disability Quarterly 31(4):187-98.

Morgan, Paul L., George Farkas, and Qiong Wu. 2011. “Kindergarten Children's Growth Trajectories in Reading and Mathematics: Who Falls Increasingly Behind?” Journal of Learning Disabilities 44(5):472-88.

Neugebauer, Martin, Marcel Helbig, and Andreas Landmann. 2011. "Unmasking the myth of the same-sex teacher advantage." European Sociological Review 27(5):669-689.

Orr, Amy J. 2011. “Gendered Capital: Childhood Socialization and the 'Boy Crisis' in Education." Sex Roles 65:271-84.

Owens, Jayanti. 2016. "Early Childhood Behavior Problems and the Gender Gap in Educational Attainment in the United States." Sociology of Education 89(3):236-58.

Parcel, Toby L., and Menaghan, Elizabeth, G. 1988. "Measuring Behavior Problems in a Large Cross Sectional Survey: Reliability and Validity for Children of the NLS Youth. Columbus: Ohio State University, Department of Sociology.

Penner, Andrew M. 2008. "Gender Differences in Extreme Mathematical Achievement: An International Perspective on Biological and Social Factors." American Journal of Sociology 114(S1):S138-70.

Penner, Andrew M. and Marcel Paret. 2008. "Gender Differences in Mathematics Achievement: 
Exploring the Early Grades and the Extremes." Social Science Research 37(1):239-53.

Peterson, James L. and Nicholas Zill. 1986. "Marital Disruption, Parent-Child Relationships, and Behavior Problems in Children." Journal of Marriage and Family 48(2):295-307.

Picho, Katherine, Ariel Rodriguez, and Lauren Finnie. 2013. "Exploring the Moderating Role of Context on the Mathematics Performance of Females Under Stereotype Threat: A MetaAnalysis." The Journal of Social Psychology 153(3):239-233.

Porche, Michelle V., Stephanie J. Ross, and Catherine E. Snow. 2014. "From Preschool to Middle-School: The Role of Masculinity in Low-Income Urban Adolescent Boys' Literacy Skills and Academic Achievement." Pp. 338-60 in Adolescent Boys: Exploring Diverse Cultures in Boyhood, edited by N. Way and J. J. Chu. New York.

Quadlin, Natasha. 2018. "Sibling Achievement, Sibling Gender, and Preferences for Parental Investment: Evidence from a National Survey Experiment." Social Forces 97(4): 16031630.

Raffaelli, Marcela, Lisa J. Crockett, and Yuh-Ling Shen. 2005. "Developmental Stability and Change in Self-Regulation From Childhood to Adolescence." The Journal of Genetic Psychology 166(1):54-76.

Ready, Douglas D., Laura F. Lo Gerfo, David T., Burkam, Valerie E. Lee. 2005. Explaining Girls’ Advantage in Kindergarten Literacy Learning: Do Classroom Behaviors Make a Difference? The Elementary School Journal 106, 21-38.

Reardon, Sean F., Erin M. Fahle, Demetra Kalogrides, Anne Podolsky, and Rosalia C. Zarate. 2018. "Gender Achievement Gaps in U.S. School Districts." American Educational Research Journal 56(6): 2474-2508.

Retelsdorf, Jan, Katja Schwartz, and Frank Asbrock. 2015. “'Michael Can’t Read!' Teachers' 
Gender Stereotypes and Boys' Reading Self-Concept.” Journal of Educational Psychology 107(1):186-94.

Riegle-Crumb, Catherine. 2006. "The Path through Math: Course-Taking Trajectories and Student Performance at the Intersection of Gender and Race/Ethnicity." American Journal of Education 113(1):101-22.

Robinson, Joseph P. and Sarah T. Lubienski. 2011. "The Development of Gender Achievement Gaps in Mathematics and Reading During Elementary and Middle School: Examining Direct Cognitive Assessments and Teacher Ratings." American Educational Research Journal 48(2):268-302.

Rothstein, Donna S., Deborah Carr, and Elizabeth Cooksey. 2019. "Cohort Profile: The National Longitudinal Survey of Youth 1979 (NLSY79).” International Journal of Epidemiology 48(1):22-22e.

Shanahan, Michael J. 2000. "Pathways to Adulthood in Changing Societies: Variability and Mechanisms in Life Course Perspective." Annual Review of Sociology 26(1):667-92.

Sokal, Laura, Herb Katz, Les Chaszewski, and Cecilia Wojcik. 2007. “Good-Bye, Mr. Chips: Male Teacher Shortages and Boys' Reading Achievement.” Sex Roles 56:651-59.

Steele, Claude M. 1997. "A Threat in the Air: How Stereotypes Shape Intellectual Identity and Performance." American Psychologist 52(6):613-29.

Stevenson, David L. and David P. Baker. 1987. "The Family-School Relation and the Child's School Performance." Child Development: 1348-1357.

Stoet, Gijsbert and David C. Geary. 2013. "Sex Differences in Mathematics and Reading Achievement Are Inversely Related: Within- and Across-Nation Assessment of 10 Years of PISA Data." PLoS ONE 8(3). 
Stricker, Lawrence J. and William C. Ward. 2008. "Stereotype Threat in Applied Settings ReExamined: A Reply.” Journal of Applied Social Psychology 38(6):1656-63.

Tenenbaum, Harriet R. and Campbell Leaper. 2003. "Parent-Child Conversations about Science: The Socialization of Gender Inequities?" Developmental Psychology 39(1):34-47.

Terrier, Camille. 2016. "Boys Lag Behind: How Teachers' Gender Biases Affect Student Achievement." IZA Discussion Paper 10343.

Tomasetto, Carlo, Francesca Romana Alparone, and Mara Cadinu. 2011. "Girls' Math Performance Under Stereotype Threat: The Moderating Role of Mothers' Gender Stereotypes." Developmental Psychology 47(4):943-49:.

Trivers, Robert L. and Dan E. Willard. 1973. "Natural Selection of Parental Ability to Vary the Sex Ratio of Offspring." Science 179(4068):90-92.

Womack, S. R., Taraban, L., Shaw, D. S., Wilson, M. N., \& Dishion, T. J. 2019. "Family turbulence and child internalizing and externalizing behaviors: Moderation of effects by race." Child Development 90(6): e729-e744.

Wout, Daryl, Henry Danso, James Jackson, and Steve Spencer. 2008. "The Many Faces of Stereotype Threat: Group- and Self-Threat." Journal of Experimental Social Psychology 44(3):792-99.

Xie, Yu and Kimberlee A. Shauman. 2003. Women in Science: Career Processes and Outcomes. Cambridge: Harvard University Press.

Yavorsky, Jill and Claudia Buchmann. 2019. "Gender Typicality and Academic Achievement among American High School Students." Sociological Science 6:661-683.

Yeung, W. Jean, John F. Sandberg, Pamela E. Davis-Kean, and Sandra L. Hofferth. 2001. "Children's Time with Fathers in Intact Families." Journal of Marriage and Family 
63(1):136-54.

Zhang, Zhiyong, John J. Mcardle, and John R. Nesselroade. 2012. "Growth Rate Models:

Emphasizing Growth Rate Analysis through Growth Curve Modeling.” Journal of Applied Statistics 39(6):1241-62. 


\section{APPENDIX}

Academic Achievement and Behavior Problems during Childhood at the Intersection of Gender and Family Environment

\section{Table of Contents}

Appendix A. Samples and number of cases in the NLSY79-CYA ......................................

Appendix B. The Early Childhood Longitudinal Study, Kindergarten Class 1998-99 ............6

Appendix C. Supplementary analyses with NLSY79-CYA ….............................................

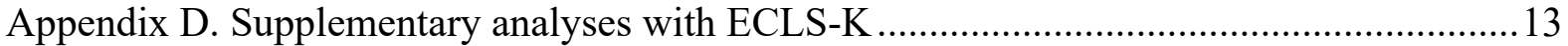




\section{Appendix A. Samples and number of cases in the NLSY79-CYA}

Table A1. Number of cases by outcome and sample

\begin{tabular}{lcccccccc}
\hline & \multicolumn{2}{c}{ Math } & \multicolumn{2}{c}{ Reading recognition } & \multicolumn{2}{c}{$\begin{array}{c}\text { Externalizing } \\
\text { problems }\end{array}$} & \multicolumn{2}{c}{$\begin{array}{c}\text { Internalizing } \\
\text { problems }\end{array}$} \\
\cline { 2 - 9 } & N-P & N-PY & N-P & N-PY & N-P & N-PY & N-P & N-PY \\
\hline Sample 1 & 9682 & 121995 & 9682 & 121995 & 9682 & 125236 & 9682 & 125236 \\
Sample 2 & 6556 & 80818 & 6439 & 79210 & 7061 & 89706 & 7083 & 90031 \\
Sample 3 & 6394 & 24530 & 6284 & 24074 & 6859 & 25948 & 6879 & 27308 \\
\hline
\end{tabular}

Note: N-P = Number of persons; N-PY = Number of person-years; Sample 1 = All observations from children born 1980 to 2002 observed at or after respective earliest age of assessment; Sample $2=$ Observations from Sample 1 from children first assessed at the respective earliest possible age; Sample $3=$ Sample 2 observations with no missing values on any variables.

Table A2. Number of cases in Sample 3 (math) by assessment and social group

\begin{tabular}{lccccc}
\hline & Age 5/6 & Age 7/8 & Age 9/10 & Age 11/12 & Age 13/14 \\
\hline All & 6394 & 5541 & 4929 & 4409 & 3257 \\
H-No-degree-F & 209 & 184 & 163 & 146 & 105 \\
H-No-degree-M & 220 & 192 & 171 & 148 & 104 \\
H-HS-degree-F & 239 & 212 & 193 & 165 & 106 \\
H-HS-degree-M & 272 & 226 & 202 & 175 & 116 \\
H-Some-college-F & 128 & 116 & 99 & 80 & 55 \\
H-Some-college-M & 132 & 107 & 94 & 80 & 53 \\
H-College-degree-F & 42 & 36 & 34 & 29 & 20 \\
H-College-degree-M & 35 & 31 & 25 & 21 & 16 \\
B-No-degree-F & 212 & 186 & 160 & 141 & 117 \\
B-No-degree-M & 227 & 203 & 185 & 166 & 117 \\
B-HS-degree-F & 406 & 359 & 326 & 284 & 209 \\
B-HS-degree-M & 392 & 344 & 302 & 256 & 195 \\
B-Some-college-F & 241 & 223 & 205 & 192 & 140 \\
B-Some-college-M & 227 & 201 & 165 & 148 & 105 \\
B-College-degree-F & 63 & 48 & 46 & 45 & 37 \\
B-College-degree-M & 75 & 68 & 60 & 49 & 32 \\
O-No-degree-F & 213 & 153 & 119 & 104 & 85 \\
O-No-degree-M & 245 & 175 & 137 & 125 & 103 \\
O-HS-degree-F & 752 & 648 & 585 & 532 & 404 \\
O-HS-degree-M & 708 & 601 & 528 & 479 & 361 \\
O-Some-college-F & 283 & 255 & 237 & 213 & 160 \\
O-Some-college-M & 329 & 291 & 258 & 234 & 178 \\
O-College-degree-F & 361 & 334 & 319 & 301 & 226 \\
O-College-degree-M & 383 & 348 & 316 & 296 & 213 \\
\hline
\end{tabular}

Note: $\mathrm{H}=$ Hispanic; $\mathrm{B}=$ Black; $\mathrm{O}=$ Other; $\mathrm{HS}=$ Highschool; $\mathrm{F}=$ Female; $\mathrm{M}=$ Male. 
Table A3. Number of cases in Sample 3 (reading recognition) by assessment and social group

\begin{tabular}{|c|c|c|c|c|c|}
\hline & Age $5 / 6$ & Age $7 / 8$ & Age $9 / 10$ & Age $11 / 12$ & Age 13/14 \\
\hline All & 6284 & 5436 & 4831 & 4335 & 3188 \\
\hline H-No-degree-F & 204 & 178 & 158 & 142 & 100 \\
\hline H-No-degree-M & 217 & 186 & 164 & 142 & 100 \\
\hline H-HS-degree-F & 234 & 206 & 191 & 162 & 104 \\
\hline H-HS-degree-M & 270 & 223 & 200 & 175 & 118 \\
\hline H-Some-college-F & 129 & 118 & 101 & 83 & 58 \\
\hline H-Some-college-M & 131 & 105 & 93 & 80 & 53 \\
\hline H-College-degree-F & 41 & 36 & 34 & 29 & 20 \\
\hline H-College-degree-M & 36 & 32 & 26 & 22 & 16 \\
\hline B-No-degree-F & 208 & 182 & 157 & 138 & 114 \\
\hline B-No-degree-M & 223 & 198 & 180 & 163 & 114 \\
\hline B-HS-degree-F & 392 & 343 & 312 & 273 & 202 \\
\hline B-HS-degree-M & 381 & 333 & 291 & 247 & 188 \\
\hline B-Some-college-F & 238 & 219 & 203 & 189 & 139 \\
\hline B-Some-college-M & 222 & 198 & 162 & 147 & 105 \\
\hline B-College-degree-F & 64 & 49 & 47 & 46 & 37 \\
\hline B-College-degree-M & 75 & 68 & 60 & 49 & 32 \\
\hline O-No-degree-F & 212 & 153 & 118 & 103 & 84 \\
\hline O-No-degree-M & 240 & 174 & 136 & 126 & 103 \\
\hline O-HS-degree-F & 734 & 633 & 571 & 520 & 389 \\
\hline O-HS-degree-M & 701 & 591 & 515 & 466 & 348 \\
\hline O-Some-college-F & 272 & 246 & 227 & 207 & 156 \\
\hline O-Some-college-M & 321 & 284 & 253 & 231 & 173 \\
\hline O-College-degree-F & 357 & 332 & 317 & 299 & 222 \\
\hline O-College-degree-M & 382 & 349 & 315 & 296 & 213 \\
\hline
\end{tabular}

Note: $\mathrm{H}=$ Hispanic; $\mathrm{B}=$ Black; $\mathrm{O}=$ Other; $\mathrm{HS}=$ Highschool; $\mathrm{F}=$ Female; $\mathrm{M}=$ Male. 
Table A4. Number of cases in Sample 3 (externalizing problems) by assessment and social group

\begin{tabular}{lccccc}
\hline & Age $4 / 5$ & Age 6/7 & Age 8/9 & Age 10/11 & Age 12/13 \\
\hline All & 6879 & 6017 & 5310 & 4801 & 4301 \\
H-No-degree-F & 229 & 194 & 169 & 146 & 123 \\
H-No-degree-M & 257 & 223 & 196 & 165 & 141 \\
H-HS-degree-F & 243 & 220 & 192 & 168 & 141 \\
H-HS-degree-M & 283 & 240 & 209 & 185 & 161 \\
H-Some-college-F & 141 & 130 & 116 & 99 & 84 \\
H-Some-college-M & 142 & 120 & 104 & 93 & 77 \\
H-College-degree-F & 46 & 37 & 32 & 27 & 20 \\
H-College-degree-M & 44 & 37 & 33 & 29 & 26 \\
B-No-degree-F & 214 & 190 & 157 & 135 & 118 \\
B-No-degree-M & 236 & 211 & 185 & 170 & 150 \\
B-HS-degree-F & 420 & 377 & 344 & 306 & 261 \\
B-HS-degree-M & 396 & 340 & 300 & 259 & 229 \\
B-Some-college-F & 256 & 229 & 207 & 186 & 167 \\
B-Some-college-M & 226 & 204 & 175 & 160 & 142 \\
B-College-degree-F & 63 & 51 & 45 & 43 & 42 \\
B-College-degree-M & 78 & 66 & 58 & 46 & 41 \\
O-No-degree-F & 250 & 187 & 134 & 121 & 111 \\
O-No-degree-M & 275 & 209 & 148 & 134 & 122 \\
O-HS-degree-F & 822 & 728 & 652 & 612 & 556 \\
O-HS-degree-M & 787 & 686 & 611 & 560 & 518 \\
O-Some-college-F & 308 & 276 & 257 & 232 & 217 \\
O-Some-college-M & 354 & 319 & 289 & 271 & 249 \\
O-College-degree-F & 392 & 369 & 347 & 334 & 317 \\
O-College-degree-M & 417 & 374 & 350 & 320 & 288 \\
\hline Note:H - & 0319 & & \\
\hline
\end{tabular}

Note: $\mathrm{H}=$ Hispanic; $\mathrm{B}=$ Black; $\mathrm{O}=$ Other; $\mathrm{HS}=$ Highschool; $\mathrm{F}=$ Female; $\mathrm{M}=$ Male. 
Table A5. Number of cases in Sample 3 (internalizing problems) by assessment and social group

\begin{tabular}{|c|c|c|c|c|c|}
\hline & Age $4 / 5$ & Age $6 / 7$ & Age $8 / 9$ & Age 10/11 & Age $12 / 13$ \\
\hline All & 6859 & 5793 & 4982 & 4405 & 3909 \\
\hline H-No-degree-F & 226 & 183 & 157 & 136 & 110 \\
\hline H-No-degree-M & 250 & 208 & 171 & 138 & 116 \\
\hline H-HS-degree-F & 243 & 216 & 185 & 162 & 135 \\
\hline H-HS-degree-M & 284 & 231 & 193 & 168 & 142 \\
\hline H-Some-college-F & 141 & 126 & 109 & 85 & 69 \\
\hline H-Some-college-M & 141 & 116 & 99 & 86 & 72 \\
\hline H-College-degree-F & 46 & 37 & 29 & 23 & 17 \\
\hline H-College-degree-M & 44 & 36 & 31 & 25 & 22 \\
\hline B-No-degree-F & 215 & 180 & 138 & 116 & 99 \\
\hline B-No-degree-M & 235 & 197 & 168 & 141 & 123 \\
\hline B-HS-degree-F & 418 & 360 & 319 & 276 & 239 \\
\hline B-HS-degree-M & 398 & 333 & 289 & 244 & 214 \\
\hline B-Some-college-F & 253 & 222 & 199 & 175 & 155 \\
\hline B-Some-college-M & 226 & 194 & 159 & 146 & 132 \\
\hline B-College-degree-F & 64 & 51 & 46 & 44 & 43 \\
\hline B-College-degree-M & 78 & 66 & 56 & 41 & 35 \\
\hline O-No-degree-F & 249 & 173 & 119 & 105 & 97 \\
\hline O-No-degree-M & 271 & 198 & 137 & 120 & 108 \\
\hline O-HS-degree-F & 818 & 702 & 617 & 569 & 510 \\
\hline O-HS-degree-M & 789 & 662 & 573 & 508 & 466 \\
\hline O-Some-college-F & 308 & 266 & 243 & 217 & 200 \\
\hline O-Some-college-M & 354 & 315 & 278 & 259 & 235 \\
\hline O-College-degree-F & 391 & 361 & 335 & 317 & 296 \\
\hline O-College-degree-M & 417 & 360 & 332 & 304 & 274 \\
\hline
\end{tabular}

Note: $\mathrm{H}=$ Hispanic; $\mathrm{B}=$ Black; $\mathrm{O}=$ Other; $\mathrm{HS}=$ Highschool; $\mathrm{F}=$ Female; $\mathrm{M}=$ Male. 


\section{Appendix B. The Early Childhood Longitudinal Study, Kindergarten Class 1998-99}

The Early Childhood Longitudinal Study, Kindergarten Class 1998-99 (ECLS-K), is a repeated survey of roughly 20,000 children who entered kindergarten in 1998 . These children attended both public and private institutions as well as part-time and full-time kindergarten programs. Data collection for the complete sample has taken place in the fall and the spring of kindergarten (1998-99), the spring of first grade (2000), the spring of third grade (2002), the spring of fifth grade (2004), and the spring of eighth grade (2007).

Each of these six waves of data collection included assessments of the students' math and reading achievement. Although these assessments were developed specifically for the ECLS-K they were based on existing instruments such as the Peabody Individual Achievement Test used in the NLSY-CYA. All results reported below are based on item response theory scores provided in ECLS-K. Analyses with the ECLS-K were limited to children who participated in the assessments starting in the first wave. We then followed the children until they completed the respective fifth assessment or were lost to follow-up. Loss to follow-up included temporary or permanent attrition but also having a missing value on any covariate or the respective assessment. Covariates are the same as in the NLSY-CYA with the exception of children's year of birth.

More information on the ECLS-K is available on the National Center for Education Statistics website: https://nces.ed.gov/ecls/kindergarten.asp 


\section{Appendix C. Supplementary analyses with NLSY79-CYA}

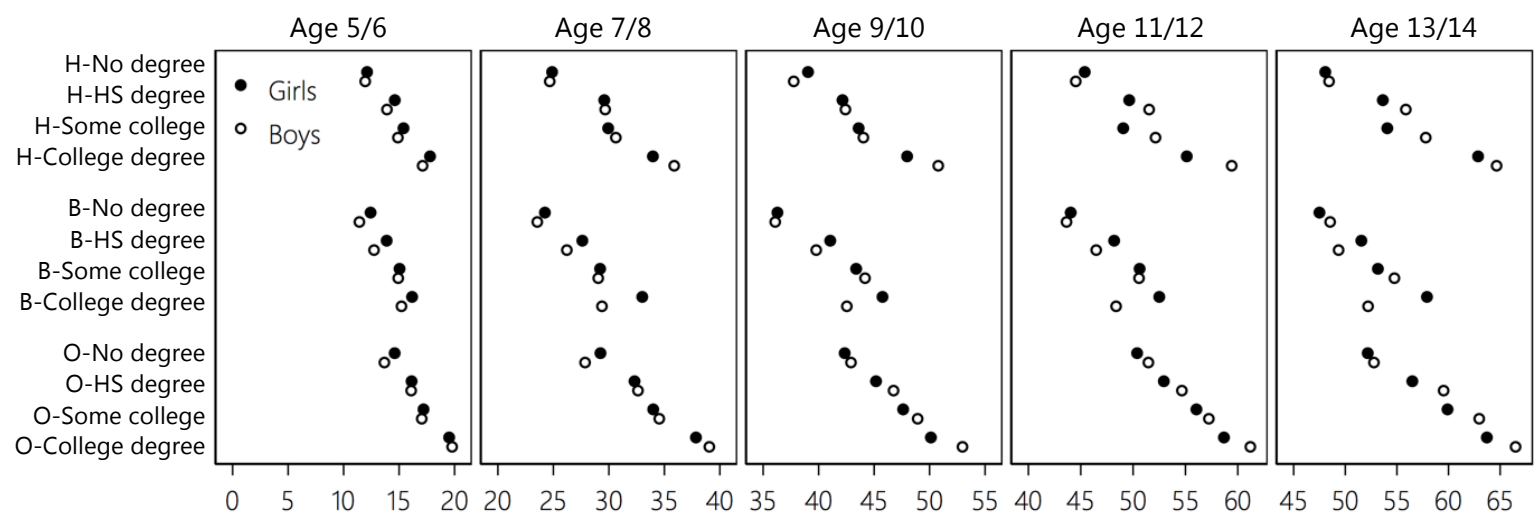

Adjusted mean

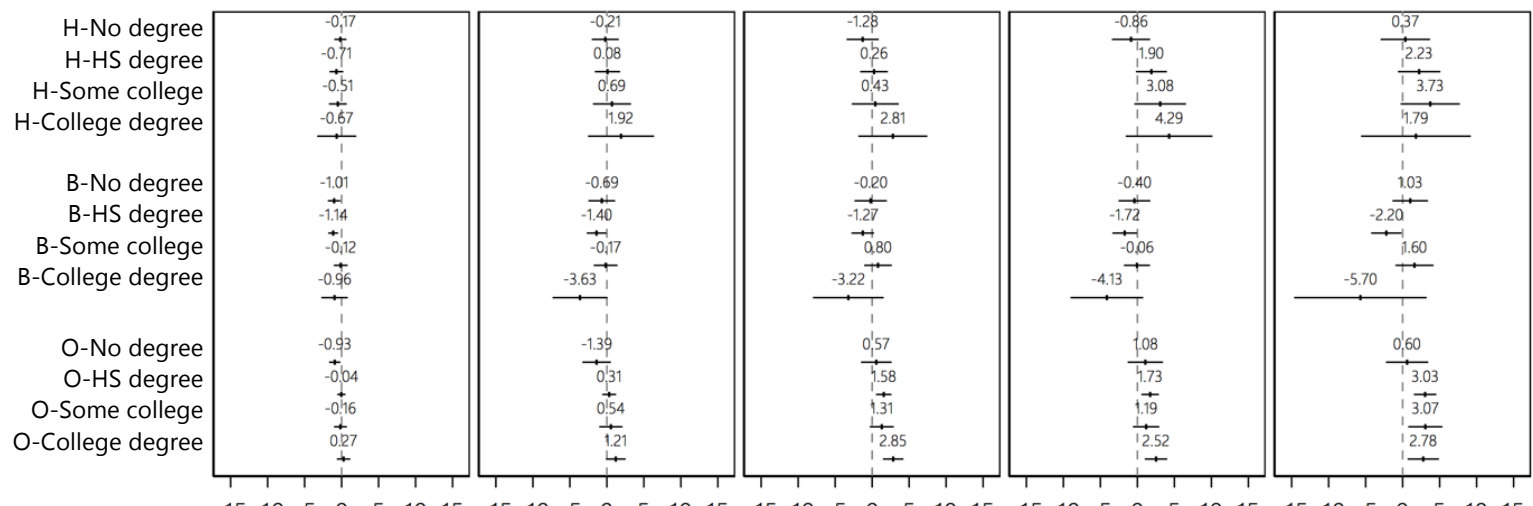

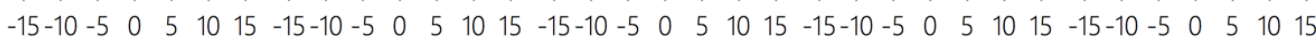

Adjusted gender mean difference (Boys-Girls)

Figure C1. Gender-specific adjusted mean math score and adjusted gender mean difference (with $95 \%$ confidence interval) by maternal education, race and age at assessment Note: $\mathrm{H}=$ Hispanic; $\mathrm{B}=\mathrm{Black} ; \mathrm{O}=$ Other; $\mathrm{HS}=$ Highschool; Estimates derived from OLS regression model described by equation 1 . 


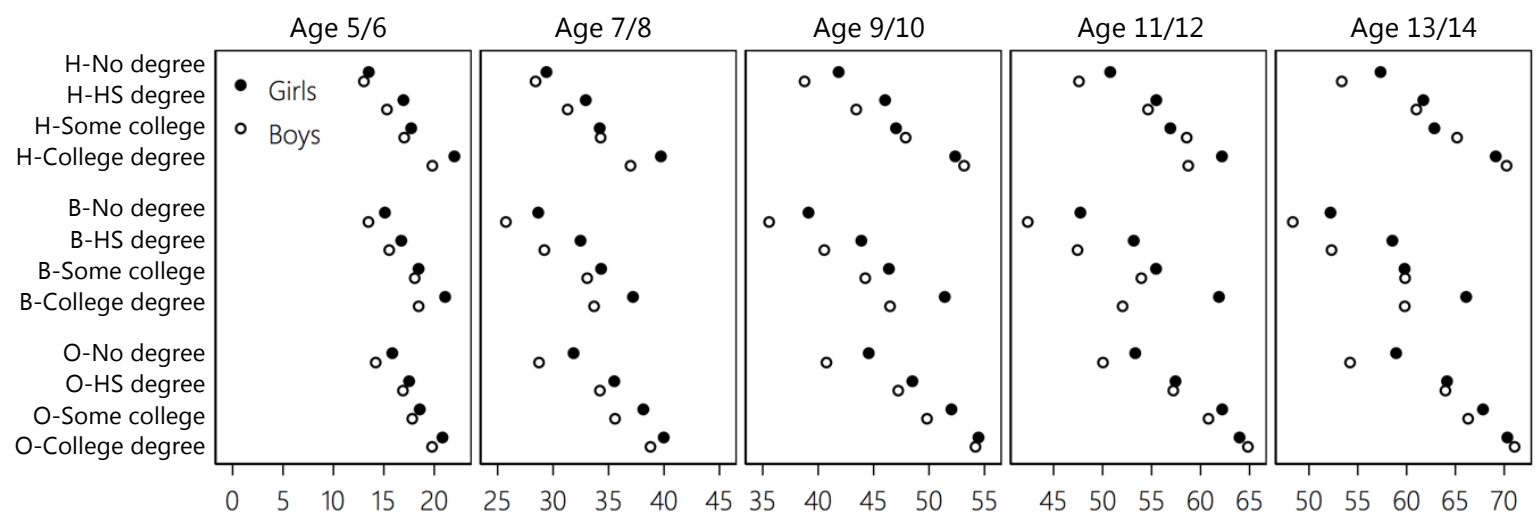

Adjusted mean

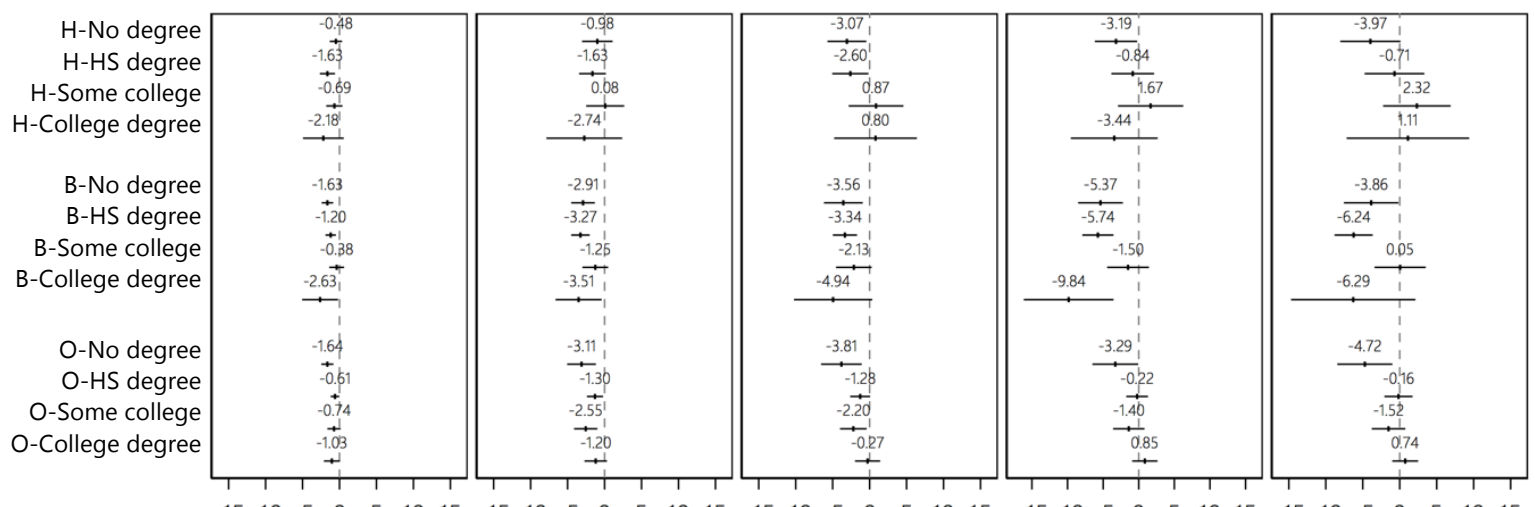

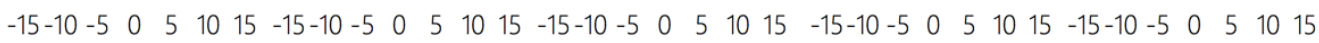

Adjusted gender mean difference (Boys-Girls)

Figure C2. Gender-specific adjusted mean reading recognition score and adjusted gender mean difference (with $95 \%$ confidence interval) by maternal education, race and age at assessment

Note: $\mathrm{H}=$ Hispanic; $\mathrm{B}=$ Black; $\mathrm{O}=$ Other; $\mathrm{HS}=$ Highschool; Estimates derived from OLS regression model described by equation 1 . 

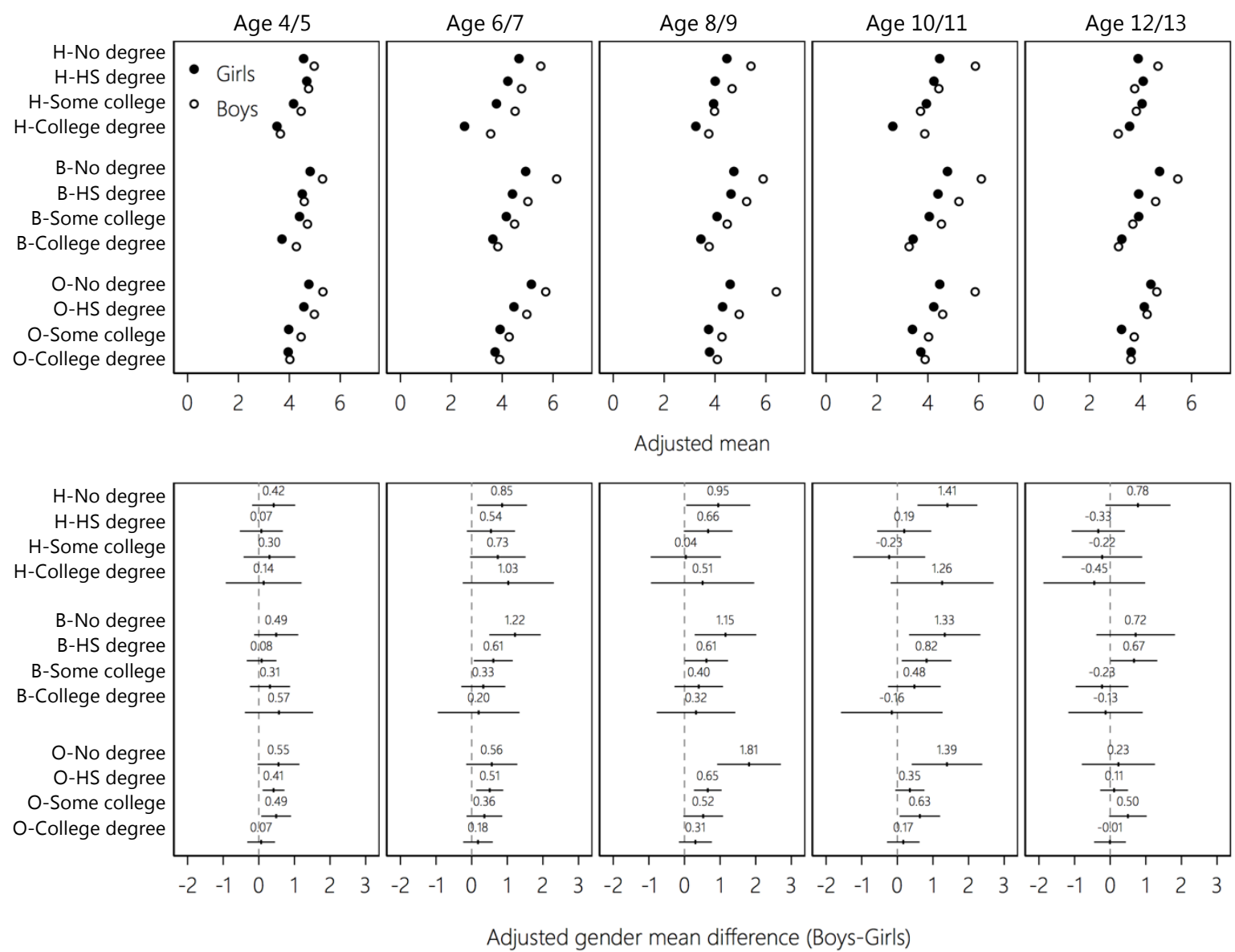

Figure C3. Gender-specific adjusted mean externalizing problems score and adjusted gender mean difference (with $95 \%$ confidence interval) by maternal education, race and age at assessment

Note: $\mathrm{H}=$ Hispanic; $\mathrm{B}=$ Black; $\mathrm{O}=$ Other; $\mathrm{HS}=$ Highschool; Estimates derived from OLS regression model described by equation 1 . 

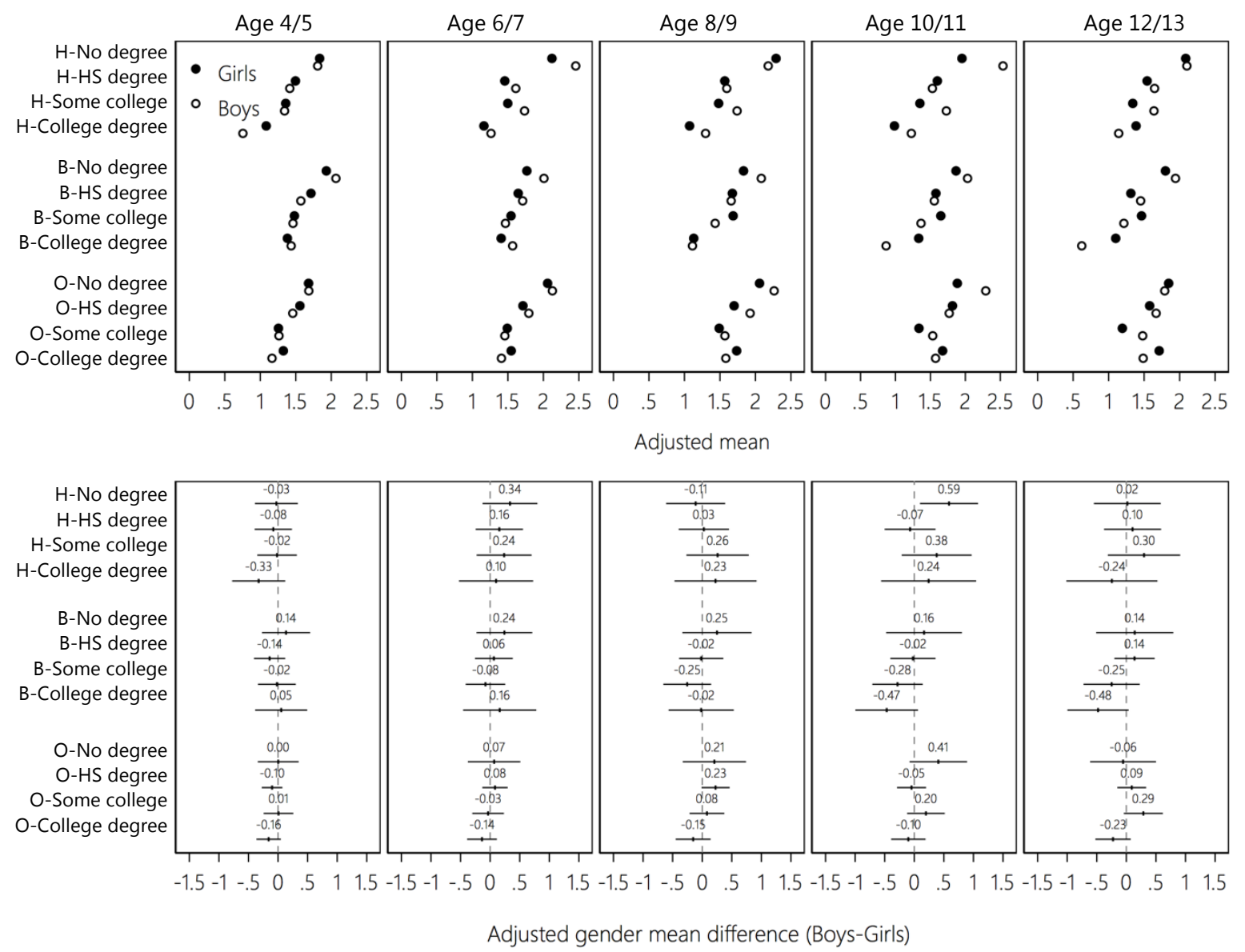

Figure C4. Gender-specific adjusted mean internalizing problems score and adjusted gender mean difference (with $95 \%$ confidence interval) by maternal education, race and age at assessment

Note: $\mathrm{H}=$ Hispanic; $\mathrm{B}=\mathrm{Black} ; \mathrm{O}=$ Other; $\mathrm{HS}=$ Highschool; Estimates derived from OLS regression model described by equation 1 . 

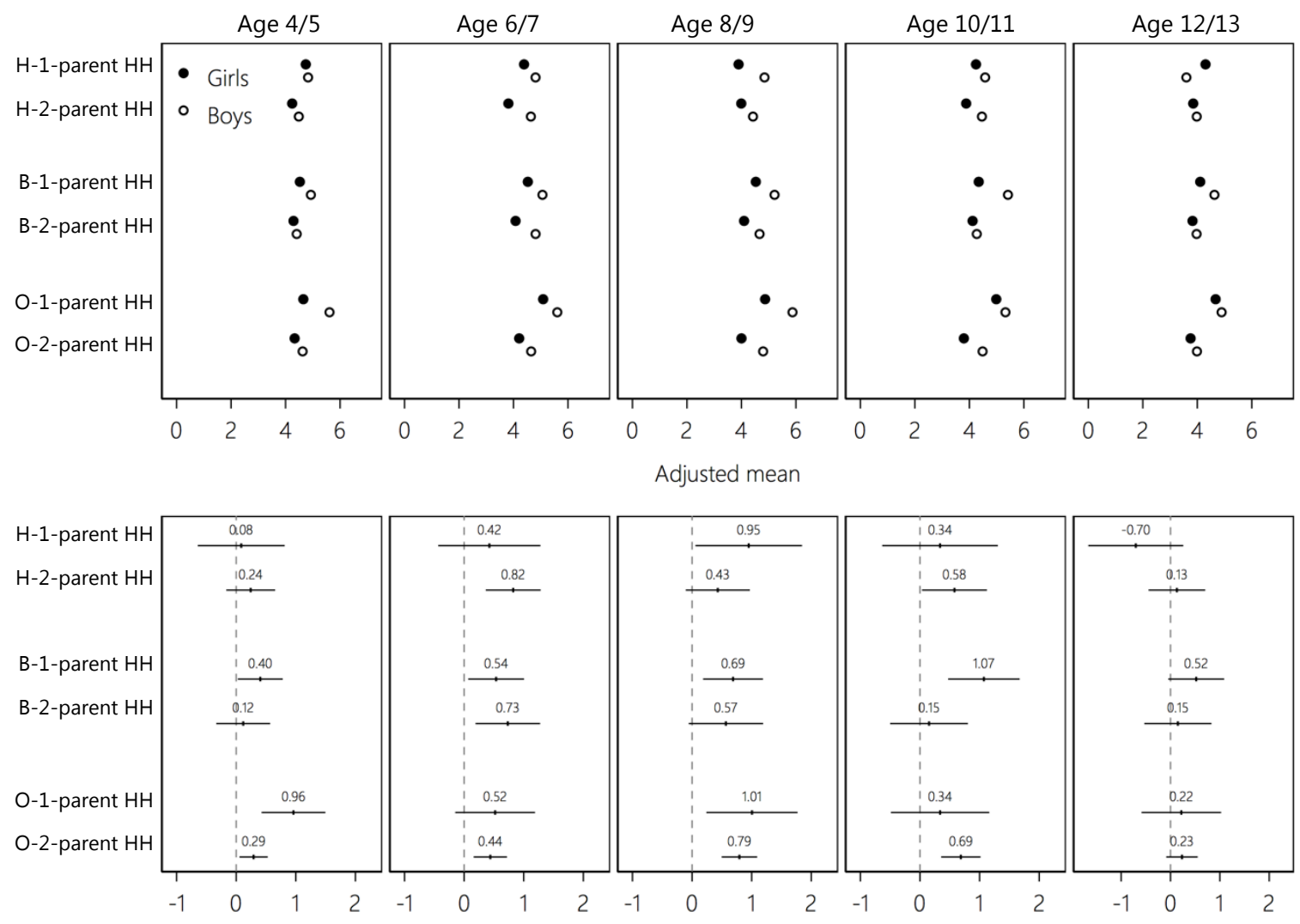

Adjusted gender mean difference (Boys-Girls)

Figure C5. Gender-specific adjusted mean externalizing problems score and adjusted gender mean difference (with $95 \%$ confidence interval) by family type, race and age at assessment Note: $\mathrm{H}=$ Hispanic; $\mathrm{B}=$ Black; $\mathrm{O}=$ Other; $\mathrm{HH}=$ Household; Estimates derived from OLS regression model described by equation 1 . 

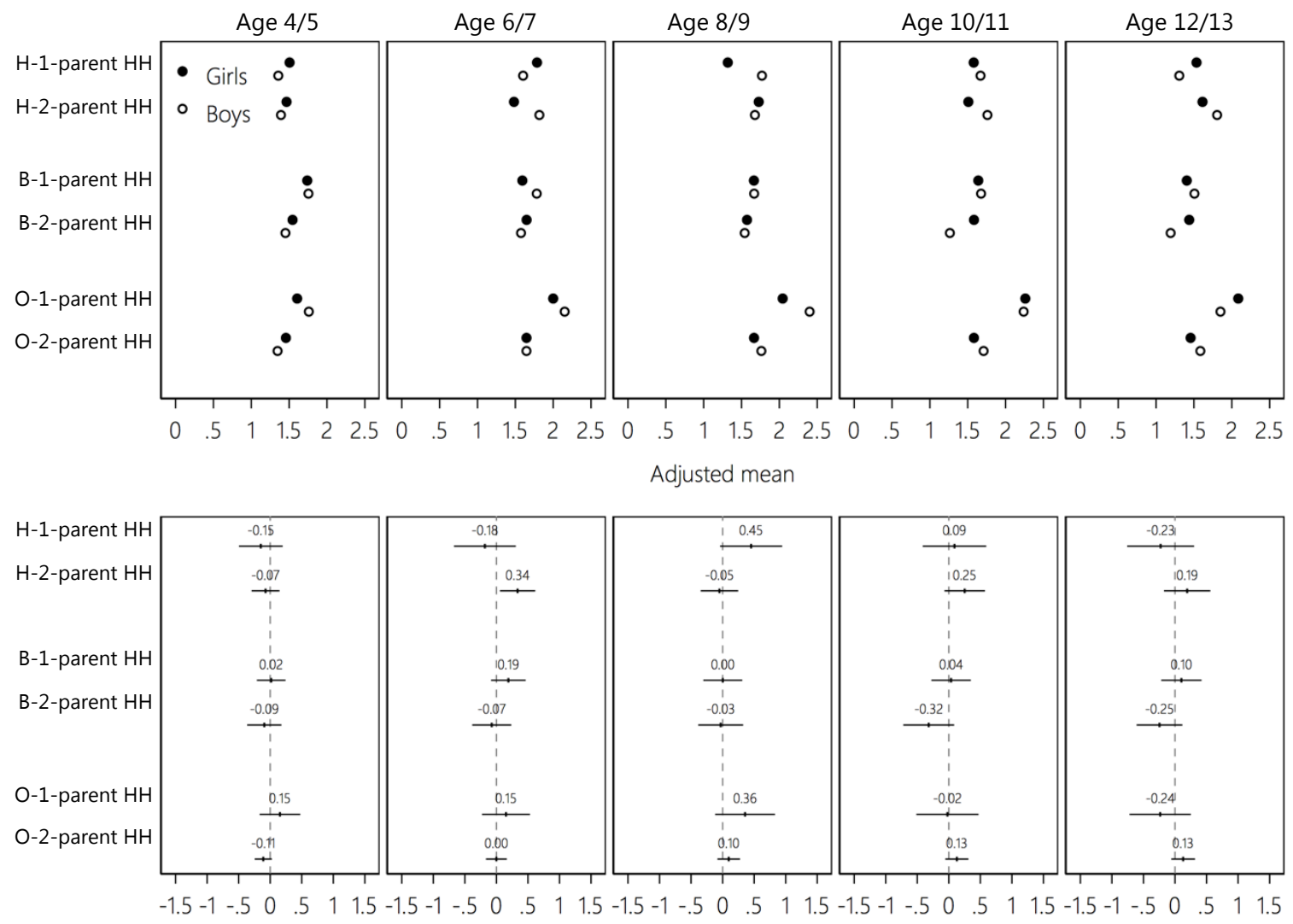

Adjusted gender mean difference (Boys-Girls)

Figure C6. Gender-specific adjusted mean internalizing problems score and adjusted gender mean difference (with 95\% confidence interval) by family type, race and age at assessment Note: $\mathrm{H}=$ Hispanic; $\mathrm{B}=\mathrm{Black} ; \mathrm{O}=$ Other; $\mathrm{HH}=$ Household; Estimates derived from OLS regression model described by equation 1 . 


\section{Appendix D. Supplementary analyses with ECLS-K}

Table D1. Summary Statistics for Academic Achievement Scores by Gender

\begin{tabular}{|c|c|c|c|c|c|c|c|}
\hline & \multicolumn{2}{|c|}{ All } & \multicolumn{2}{|c|}{ Girls } & \multicolumn{2}{|c|}{ Boys } & \multirow[b]{2}{*}{ p-value } \\
\hline & $\mathrm{M}$ & (sd) & $\mathrm{M}$ & (sd) & $\mathrm{M}$ & (sd) & \\
\hline \multicolumn{8}{|l|}{ Math } \\
\hline G-K (F) & 26.16 & $(9.17)$ & 26.03 & $(8.48)$ & 26.29 & $(9.79)$ & 0.07 \\
\hline G-K (S) & 36.71 & (12.11) & 36.38 & (11.13) & 37.03 & (12.98) & 0.00 \\
\hline G-1 & 62.07 & (18.08) & 61.12 & (16.79) & 62.99 & (19.22) & 0.00 \\
\hline G-3 & 100.01 & $(24.49)$ & 97.66 & $(23.48)$ & 102.35 & $(25.23)$ & 0.00 \\
\hline G-5 & 125.13 & $(24.27)$ & 122.45 & $(24.12)$ & 127.85 & $(24.13)$ & 0.00 \\
\hline G-8 & 143.55 & $(21.31)$ & 142.31 & $(20.92)$ & 144.82 & $(21.62)$ & 0.00 \\
\hline \multicolumn{8}{|l|}{ Reading } \\
\hline G-K (F) & 35.47 & (10.33) & 36.10 & $(10.15)$ & 34.86 & $(10.47)$ & 0.00 \\
\hline G-K (S) & 46.93 & $(14.15)$ & 48.00 & (14.11) & 45.89 & $(14.11)$ & 0.00 \\
\hline G-1 & 78.87 & $(23.83)$ & 80.94 & $(23.40)$ & 76.86 & $(24.07)$ & 0.00 \\
\hline G-3 & 129.93 & $(27.13)$ & 132.37 & $(26.23)$ & 127.50 & $(27.79)$ & 0.00 \\
\hline G-5 & 153.77 & $(24.81)$ & 155.32 & $(23.76)$ & 152.19 & $(25.75)$ & 0.00 \\
\hline G-8 & 174.58 & $(25.52)$ & 176.65 & $(24.14)$ & 172.45 & $(26.71)$ & 0.00 \\
\hline
\end{tabular}

Note: $\mathrm{G}=$ Grade $; \mathrm{K}=$ Kindergarten; $\mathrm{F}=$ Fall; $\mathrm{S}=$ Spring. P-values pertain to two-tailed t-tests of mean differences by gender. 

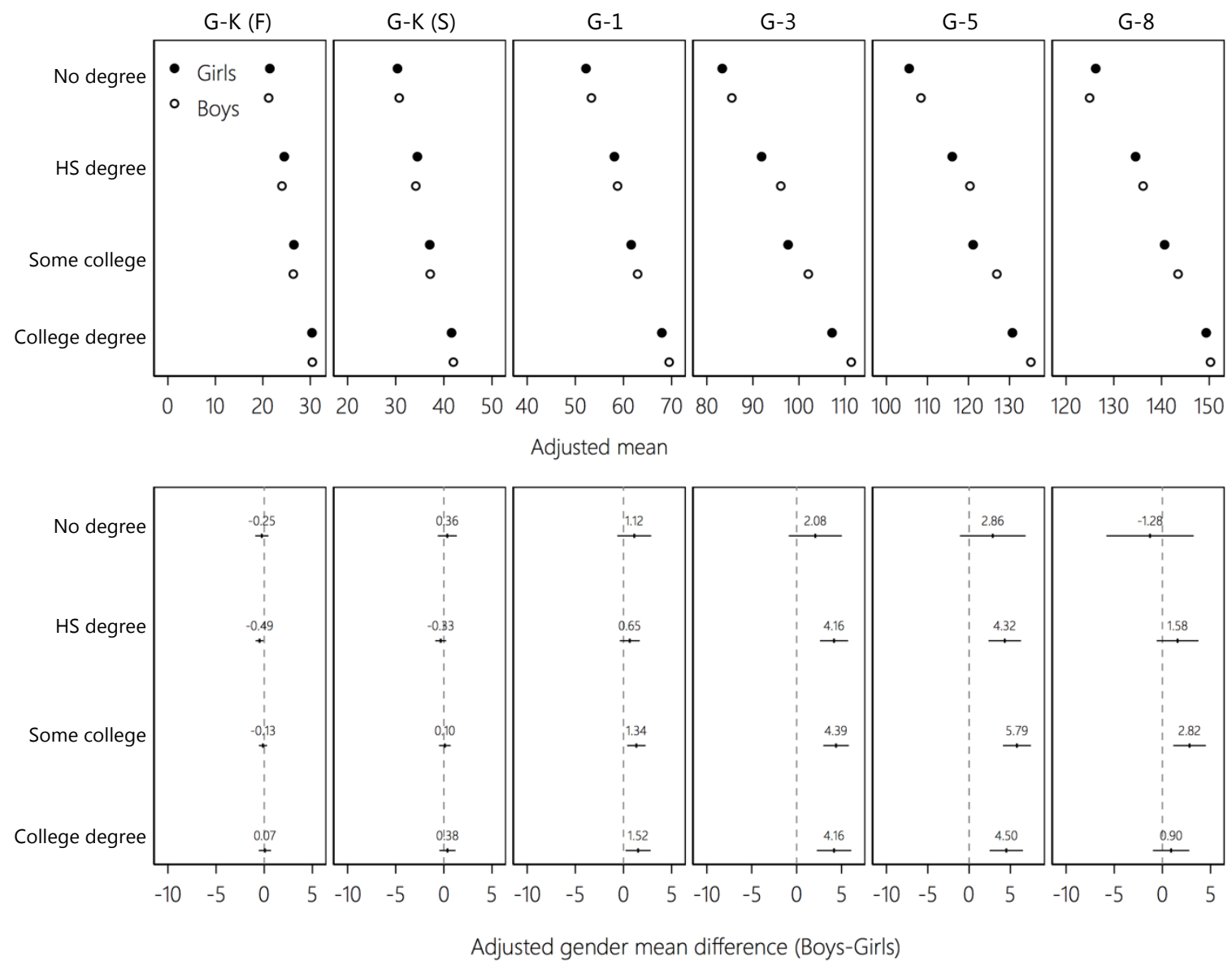

Figure D1. Gender-specific adjusted mean math score and adjusted gender mean difference (with $95 \%$ confidence interval) by maternal education and age at assessment Note: $\mathrm{G}=$ Grade; $\mathrm{K}=$ Kindergarten; $\mathrm{F}=$ Fall; $\mathrm{S}=$ Spring; $\mathrm{HS}$ = Highschool; Estimates derived from OLS regression model described by equation 1 . 

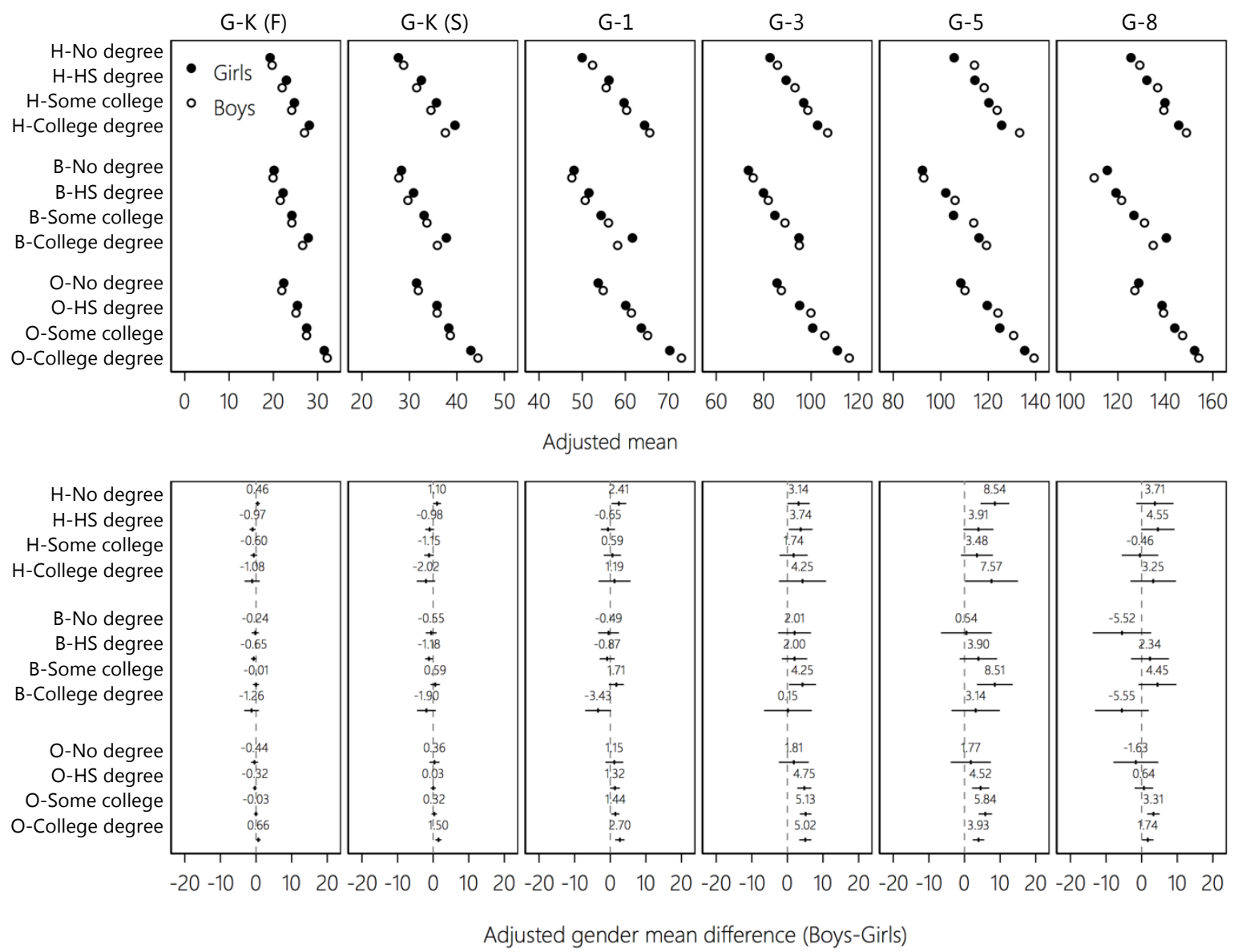

Figure D2. Gender-specific adjusted mean math score and adjusted gender mean difference (with $95 \%$ confidence interval) by maternal education, race and age at assessment Note: $\mathrm{G}=$ Grade $; \mathrm{K}=$ Kindergarten; $\mathrm{F}=$ Fall; $\mathrm{S}=$ Spring; $\mathrm{H}=$ Hispanic $; \mathrm{B}=$ Black; $\mathrm{O}=$ Other; $\mathrm{HS}=$ Highschool; Estimates derived from OLS regression model described by equation 1 . 

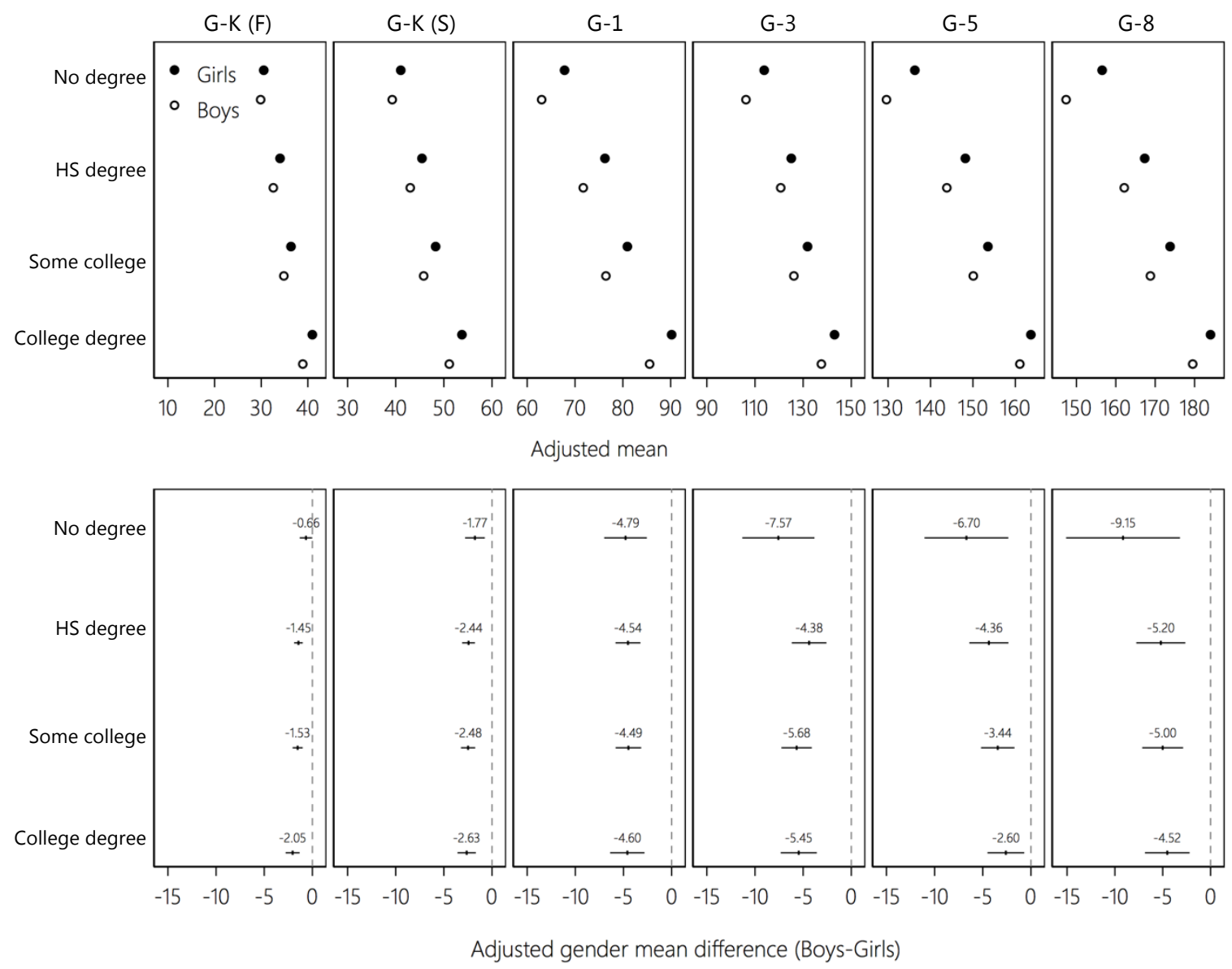

Figure D3. Gender-specific adjusted mean reading score and adjusted gender mean difference (with 95\% confidence interval) by maternal education and age at assessment Note: $\mathrm{G}=$ Grade; $\mathrm{K}=$ Kindergarten; $\mathrm{F}=$ Fall; $\mathrm{S}=$ Spring; $\mathrm{HS}=$ Highschool; Estimates derived from OLS regression model described by equation 1 . 

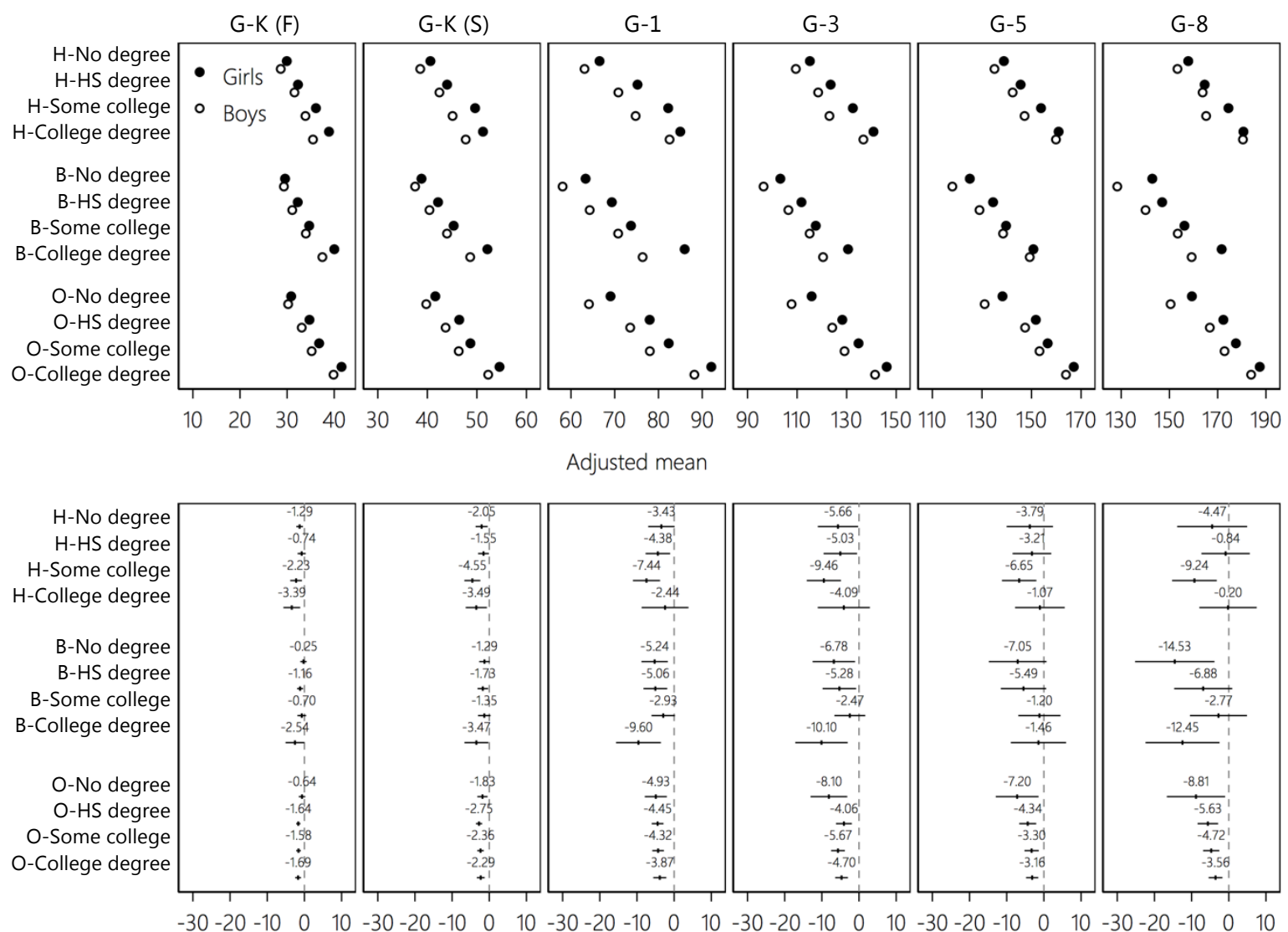

Adjusted gender mean difference (Boys-Girls)

Figure D4. Gender-specific adjusted mean reading score and adjusted gender mean difference (with 95\% confidence interval) by maternal education, race and age at assessment Note: $\mathrm{G}=$ Grade; $\mathrm{K}=$ Kindergarten; $\mathrm{F}=$ Fall; $\mathrm{S}=$ Spring; $\mathrm{H}=$ Hispanic; $\mathrm{B}=$ Black; $\mathrm{O}=$ Other; $\mathrm{HS}=$ Highschool; Estimates derived from OLS regression model described by equation 1. 

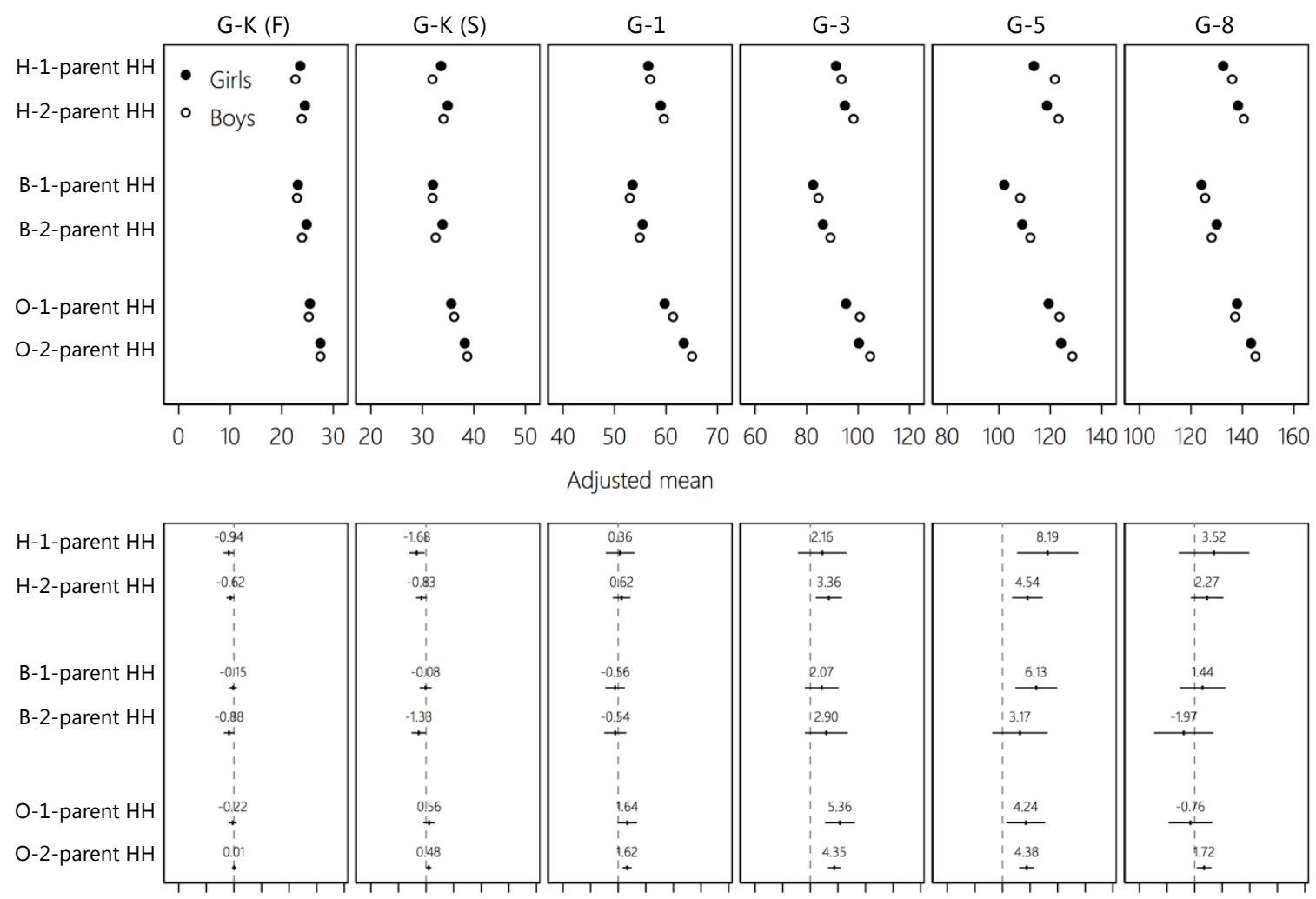

$-10-50510152(-10-50510152(-10-50510152(-10-50510152(-10-505510152(-10-505101521$

Adjusted gender mean difference (Boys-Girls)

Figure D5. Gender-specific adjusted mean math score and adjusted gender mean difference (with 95\% confidence interval) by family type, race and age at assessment Note: $\mathrm{G}=$ Grade; $\mathrm{K}=$ Kindergarten; $\mathrm{F}=$ Fall $; \mathrm{S}=$ Spring; $\mathrm{H}=$ Hispanic; $\mathrm{B}=$ Black; $\mathrm{O}=$ Other; $\mathrm{HH}=$ Household; Estimates derived from OLS regression model described by equation 1. 

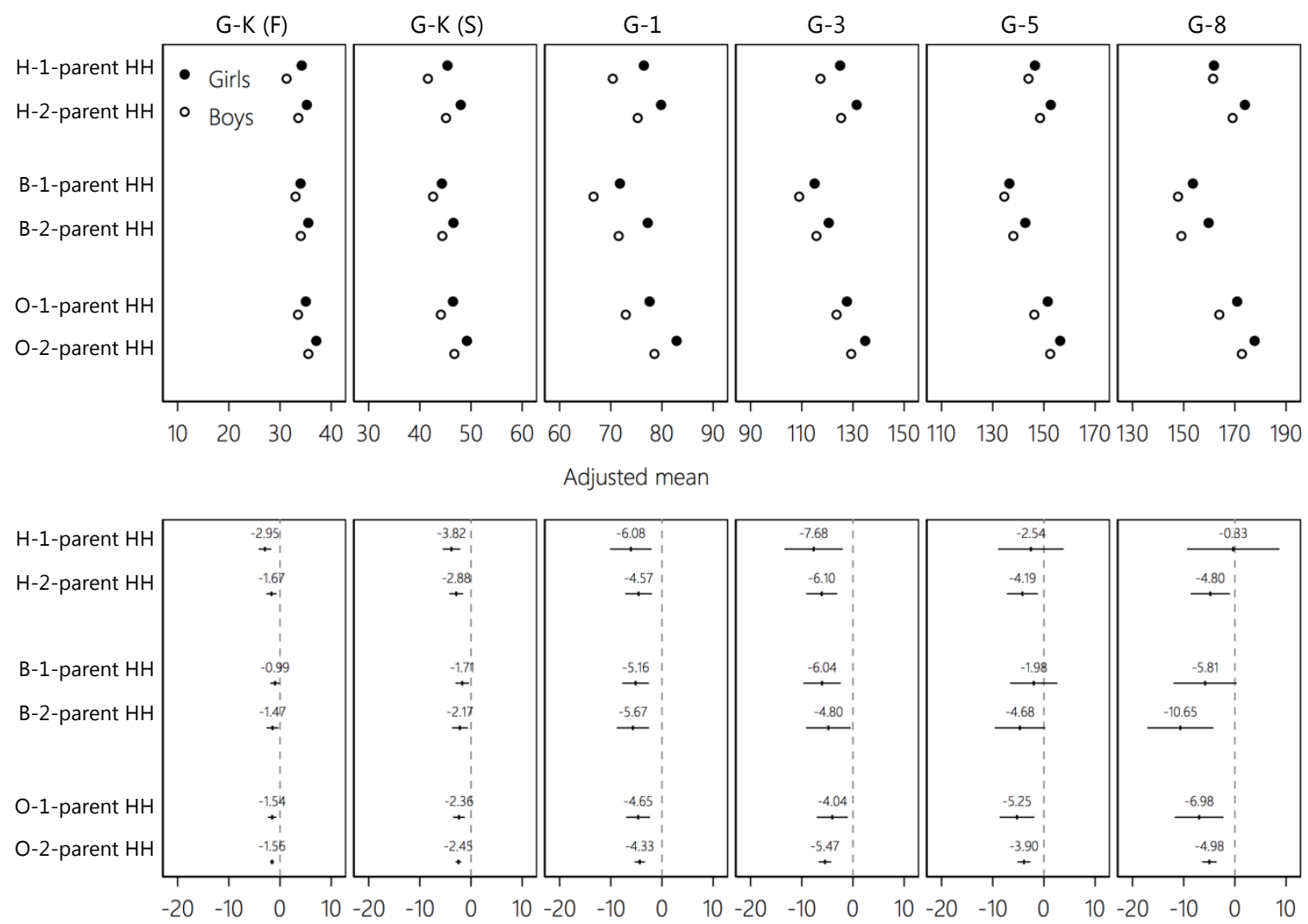

Adjusted gender mean difference (Boys-Girls)

Figure D6. Gender-specific adjusted mean reading score and adjusted gender mean difference (with 95\% confidence interval) by family type, race and age at assessment Note: $\mathrm{G}=$ Grade $; \mathrm{K}=$ Kindergarten; $\mathrm{F}=$ Fall; $\mathrm{S}=$ Spring; $\mathrm{H}=$ Hispanic $; \mathrm{B}=$ Black; $\mathrm{O}=$ Other $\mathrm{HH}=$ Household; Estimates derived from OLS regression model described by equation 1. 